ÖSTERREICHISCHE

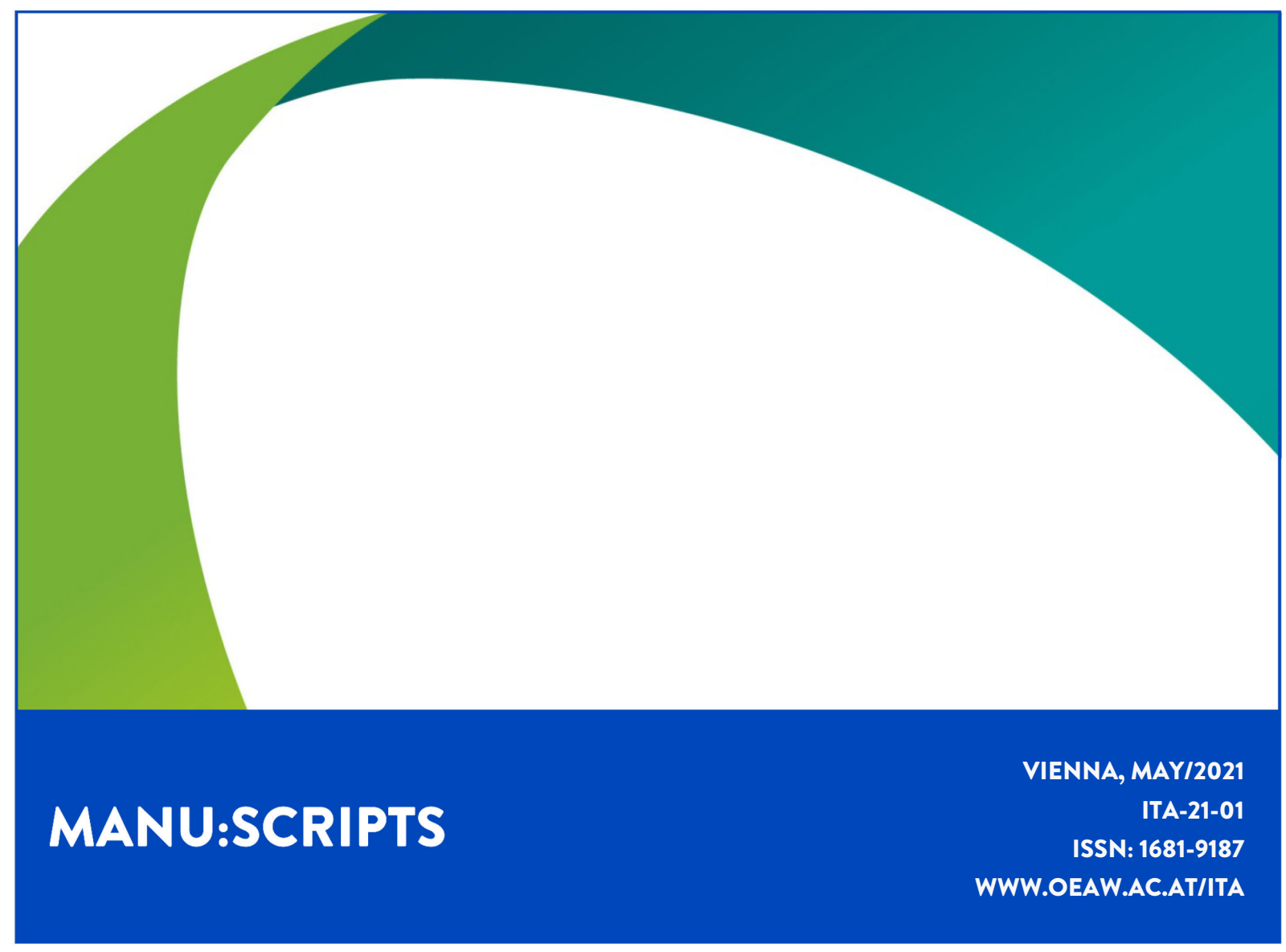

\title{
THREE DECADES OF INSTITUTIONALISED TA IN AUSTRIA
}

THE INSTITUTE OF TECHNOLOGY ASSESSMENT OF THE AUSTRIAN ACADEMY THE SCIENCES

\section{.}





\section{THREE DECADES OF INSTITUTIONALISED TA IN AUSTRIA}

\section{THE INSTITUTE OF TECHNOLOGY ASSESSMENT OF THE AUSTRIAN ACADEMY THE SCIENCES}

\section{MICHAEL NENTWICH AND DANIELA FUCHS}

This article first appeared in German in the journal "Geistes-, Sozial- und Kulturwissenschaftlichen Anzeiger" of the Austrian Academy of Sciences, vol. 153 (2018), pp. 5-68. It has been translated but not updated in February 2021. The authors would like to thank the interviewees for their time and the many colleagues who gave feedback to the original article. Special thanks go to the Austrian Academy of Sciences archive staff, without whom this article would not have been possible. Many thanks also to Tanja Sinozic-Martinez, who helped us polishing our English translation.

\section{KEYWORDS}

technology assessment, history, Austrian Academy of Sciences, interdisciplinarity, policy advice, Austrian Parliament

\section{ABSTRACT}

This article describes in detail the three-decades-long development of institutionalised technology assessment (TA) in Austria. The storyline starts in the early 1980s, leading to the foundation of the first TA working group at a pre-existing research institute of the Austrian Academy of Sciences in 1985. This group was later detached as an individual unit and developed into the Institute of Technology Assessment in 1994. In the second main section, the authors analyse longitudinal developments, including: the advances of the thematic portfolio; the on-off relationship to Parliament over time; the increasing international standing and networking activities; the growth in staff; and the advances of outreach and public communication; all leading to the ITA as it is known today. 


\section{MASTHEAD}

\section{Media owner:}

Austrian Academy of Sciences (ÖAW)

Legal person under public law (BGB1 569/1921 idF BGB1 I 31/2018)

Dr. Ignaz Seipel-Platz 2, A-1010 Vienna

\section{Editor:}

Institute of Technology Assessment (ITA)

Apostelgasse 23, A-1030 Vienna

www.oeaw.ac.at/ita

ITA manu:scripts appear at irregular intervals and publish working papers and talks from staff members as well as guests. ITA manu:scripts are exclusively made available to the public via the Internet portal "epub.oeaw": epub.oeaw.ac.at/ita/ita-manuscriptITA-manu:script

No.: ITA-21-01 (May/2021)

ISSN-online: 1818-6556

epub.oeaw.ac.at/ita/ita-manuscript/ita_21_01.pdf

(c) (i) This report is published under the Creative Commons Attribution 4.0 International License: creativecommons.org/licenses/by/4.0/ 


\section{CONTENT}

THE INSTITUTIONAL DEVELOPMENT OF TA AT THE AUSTRIAN ACADEMY OF SCIENCES..................................................8 EARLY YEARS AS A RESEARCH UNIT (1988-1991): ESTABLISHMENT UNDER FINANCIAL AND INSTITUTIONAL UNCERTAINTY DEVELOPING THE SCIENTIFIC BASE AND EVALUATION: FROM RESEARCH UNIT TO INSTITUTE (1991-1994) ............. 18 DIVERSIFICATION AND CONSOLIDATION OF TA IN AUSTRIA: THE FIRST DECADE AS A RESEARCH INSTITUTE (1994-2005) 20 EXPANDING AND BROADENING TOPICS, GENERATIONAL CHANGE AND CRISIS (2006-2011)..................................23

\section{FIGURES}

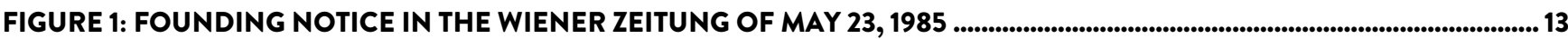

FIGURE 2: THE OEAW RESEARCH INSTITUTIONS REGARDING TA 1971 TO 2018..............................................................................15

FIGURE 3: THE FIRST DOOR SIGN OF THE TAU AND FOLLOWING DOOR SIGNS OF THE ITA.....................................................16

FIGURE 4: ERNEST BRAUN (LEFT) AND CHRISTIAN RAKOS (RIGHT) PRESENT AT THE OECD CONFERENCE ON

\section{TABLES}

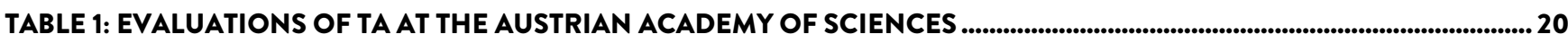

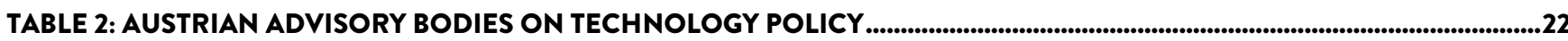

TABLE 3: ADVISORY BODIES FOR TA IN AUSTRIA $\ldots \ldots \ldots \ldots$

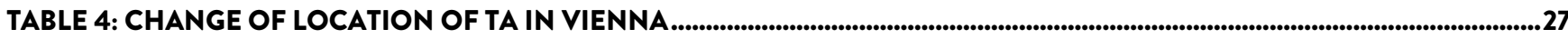





\section{INTRODUCTION}

Technology Assessment (TA) is a field of research and practice of scientific policy advice on socially sensitive technology issues. First founded as an independent advisory body to the US Congress in the form of the Office of Technology Assessment (OTA, 1972-1995), TA approaches have developed and differentiated in various ways. During the 1980s, TA became institutionalized at several parliaments in Europe (GANZEVLES et al. 2012), especially in France, the UK and Germany. Besides, TA was increasingly established at universities and research institutions and diversified its methodologies. Since the turn of the millennium, TA has also begun to spread in Asia (South Korea, Japan) and Latin America (Mexico, Chile). Especially the model of expert-oriented, parliamentary TA serves as a role model for institutionalization.

The history of TA in Austria is closely linked to the foundation and development of the current Institute of Technology Assessment (ITA) at the Austrian Academy of Sciences (ÖAW). Here we investigate its foundation, establishment, and further development from the mid-1980s until early 2018. It illustrates the successful experiment of institutionalising an emerging, advisoryoriented field of research within an established and continuously evolving scientific landscape. In retrospect, it becomes clear that this development is an institutional achievement of the Austrian Academy of Sciences as a whole: in the medium term, the Academy, specialised in basic research and organised on a multi- but not interdisciplinary basis, productively dealt with a completely new, highly interdisciplinary field of research with a high degree of orientation towards application and external contracting authorities. Furthermore, she succeeded in successively creating nurturing conditions for a sustainable and successful long-term establishment. Therefore, we interpret the history of TA at the Austrian Academy of Sciences as out-comes of tensions and conflicts that arise when TA is institutionalised at a public scientific institution. Similarly, a balancing act between mono- or multidisciplinary versus interdisciplinary approaches, between pure research orientations (including the criteria of excellence) and orientations towards societal needs (transdisciplinarity), between science-for-policy versus policy-for-science, and between expert orientation versus openness to new methodological, e.g. participatory, methods has always accompanied TA activities. This balancing act continues wherever TA leaves its mark in the scientific landscape and public perception.

This article first chronologically documents the different phases of development of the institute, each presenting specific challenges for establishing and further advancing the research field. We distinguish between the following phases: its "prehistory" (until 1984), the establishment of the working group (1984/85) and its first years (1985-1987), the research unit at the Academy (1988-1991), the establishment of the Institute (1991-1994), the first ten years as an Institute (1994-2005), generational changes and crisis years (2006-2011) and the most recent development (2011-2017). Subsequently, we analyse specific aspects through the more than thirty years of history: the dynamics of the research portfolio, relations with parliament, international networking, personnel development and public communication. Finally, we review the first thirty years of technology assessment at the Austrian Academy of Sciences and give a brief outlook.

The two authors are themselves staff members of the institute described here, and therefore we write from an internal perspective. Especially the first author is deeply connected to its his-tory, as he was one of the first employees of the Technology Assessment Unit (TAU), was not continuously but for many years its employee, and is director of the ITA since 2006. This provides a specific perspective to this historical account, while at the same time ensuring privileged access to sources and individual memories that were often helpful for the research. Additional perspectives were introduced on the one hand by the fact that the second author did not experience most of the story herself, and on the other hand, by primarily making use of objectifiable sources. We base this article on intensive research in the archives of the Austrian Academy of Sciences, on the ITA file archive, on the institute's internal databases (on projects and staff) as well as on historical preparatory work (RAKOS 1988; TICHY 1997; PEISSL 1997; PEISSL/TICHY 1999; TICHY 2004; PEISSL/NENTWICH 2005). On the other hand, in addition to literature and archive material, we conducted fourteen formal interviews with contemporary witnesses (length: approx. 60-120 minutes) and numerous informal conversations with people from outside and inside the institute. In addition to long-standing or former employees of the Institute, the interviewees included actors from the Academy of Sciences, politics, administration, and the Institute's university environment. ${ }^{1}$

1 Our interview partners were (in chronological order of the interviews): Paschke, Fritz; Schneider, Wilhelm; Schmutzer, Manfred; Bruckmann, Gerhart; Fleissner, Peter; Rakos, Christian; Latzer, Michael; Rozsenich, Nobert; Schmitzer, Eva-Maria; Wild, Claudia; Peissl, Walter; Torgersen, Walter; Čas, Johann. The interview transcripts are quoted here anonymously according to the following scheme: "(I01)", for the interview with number 1 , etc. - the numbering was admittedly not chronological to preserve anonymity. 


\section{THE INSTITUTIONAL DEVELOPMENT OF TAAT THE AUSTRIAN ACADEMY OF SCIENCES}

\subsection{A FIELD OF RESEARCH GAINS INTEREST: "PREHISTORY" (UNTIL 1984)}

Anchored between scientific research work and application-oriented policy advice, technology assessment (TA) is influenced by the political context more significantly than other scientific fields and strongly embedded in the political system in which it operates. Originated in the USA, it became established in Europe in various political contexts. In 1972, the Office of Technology Assessment (OTA) was founded in the US to provide independent information and advice on the US Congress's scientific and technological issues. While the OTA was practically closed in 1995 by a parliamentary majority (SADOWSKI 2015), its approaches and working methods had a lasting influence on the concepts of European TA institutes. For ex-ample, Ernest Braun, the first head of the working group on technology assessment at the Austrian Academy of Sciences, referred to the original proposal of Congressman Emilio Daddario on TA in his plea for the institutionalisation of TA in Austria at the National Day Symposium “Technology and Society” in October 1984:

"Technology assessment is a form of policy research which provides a balanced appraisal to the policymaker. Ideally, it is a system to ask the right questions and obtain correct and timely answers. It identifies policy issues, assesses the impact of alternative courses of action and presents findings. It is a method of analysis that systematically appraises the nature, significance, status, and merit of a technological progress" (BRAUN 1984, 10)

According to the OTA model, Braun envisioned a TA institute, which would take on a direct advisory function for policymakers on technology issues by incorporating diverse expertise. It soon became clear that a direct transfer of the OTA model to European and especially Austrian conditions would not succeed. Reasons for this were later identified both as a fundamental difference in the balance of power between parliament and administration - the latter tended to be stronger than the parliament - and in the difficult relationship between science and policy advice given the "fear of contact between science and politics, typical for Europe" (TICHY 1997, translated by authors). Consequently, the actors sought more acceptable possibilities to establish TA in Austria.

The Austrian Academy of Sciences (OeAW) of course paid attention to social problems prior to these events. The Academy took note of the foundation of the "Club of Rome" (1968) and the resulting innovations in the field of statistics and future prognoses. The presentation of "system dynamics" (the basis for the later work of D. and D. Meadows "The limits of growth", MEADOWS et al. 1972) at a meeting of the Club in Berne by Jay Wright Forrester and his sub-sequent visit to Vienna inspired Gerhardt Bruckmann, member of the OeAW, to give a lecture on "Exact Methods in Futurology" (BRUCKMANN 1971) at the general meeting of the OeAW on 10 December 1971. This talk directly led - noteworthy for the further development of TA in Austria - to the foundation of the Commission for Future Studies of the Austrian Academy of Sciences under his leadership. After being renamed "Commission for Socioeconomic Development Research" and being transformed into an institute („Institute for Socioeconomic Development Research”, ISOZÖK, 1973), this Commission will become the first home of the Working Group on Technology Assessment years later (1985) (I01) (Figure 1). The Commission for Futures Studies conducted interdisciplinary systems analysis, drawing on Jay Wright Forrester's "World Model", improving it and adapting it to Austrian conditions. Planned subareas of the model included "the population system, the economic system (including tourism and ecology), the reproductive system (consumption structure, education, housing, transport), the system of social security and social control, and the political system" (FLEIBNER 1973, 1, translated by authors). If necessary, the quantification of functional interdepend- 
encies involved the opinions of experts and those affected. The model's pictures of the future were not under-stood as reliable predictions but rather as opportunities for socio-economic development. The application of such models was seen in participatory planning and as a tool for facilitating new learning processes of those affected and involved. "By explicating preconditions and contexts, the model can be used to develop a deeper understanding of the political and economic constraints and restrictions of our social formation, which the usual technocratic planning approaches neglect often". (FLEIBNER 1973, 2, translated by authors).

Simultaneously, technicians and computer scientists began to take an interest in the consequences of their work, especially in the emerging field of microelectronics. Through publications such as "Revolution in miniature" (BRAUN/MACDONALDS 1982 [1978]), impact assessment in microelectronics became the subject of discussion among experts (I04). Therefore, it is not surprising that the Federal Ministry of Science and Research later funded the first TA projects in Austria under its priority area of microelectronics.

After early attempts to address the topic of science, or technology and society, more broadly, the symposium "Technology and Society" in Lech am Arlberg offered a first opportunity for the topic to be acknowledged by science policy and the broader public. This symposium was organised by the TU Vienna in August 1980, opened by the then Minister of Science and Research, Herta Firnberg, and attended by some of the key players later on in the field, including Manfred Schmutzer, Fritz Paschke, and Ernest Braun. Eventually, Ernest Braun was willing to establish the field of "Technology and Society" in Austria. ${ }^{2}$

Initially, TU Vienna attempted to establish "Technology and Society" as a research and teaching topic (I09). A corresponding working group convened as late as 1980; two interfaculty Senate Commissions prepared postgraduate studies to combine economic-legal and ecological concerns into the continuing education of engineers. ${ }^{3}$ Eventually, the Research Institute for Technology and Society (in German FTG and later ITG) was established based on a trust (Stiftung) of the Federation of Austrian Industry named after its president from 1972-1980, Hans Igler, and opened by Federal Minister Firnberg in November 1982. The FTG/ITG gave "special attention and research of the interaction of 'technology - economy - society' in technical studies for teaching and practice". ${ }^{4}$ Professor Kühne became the first head of the institute, the first staff member as of mid-1983 (and later on head of the Institute for many years) as Manfred Schmutzer. ${ }^{5}$ The ITG existed until Schmutzer ${ }^{6}$ retired.

Ernest Braun had presented the concept of technology assessment in Lech. He was appoint-ed a visiting professor by Aston University (Birmingham) at TU Vienna (1982/83) during the founding phase of the ITG but was not directly involved in the founding process. He moved to the Institute of Physics at the University of Vienna for 1983/84 as a visiting professor. However, he remained in contact with his colleagues at the TU Vienna. At the National Holiday Symposium in October 1984 on "Technology and Society", Braun in his lecture "Technology Policy and its Information Needs", referred to the state's duty to promote the common good (BRAUN 1984) above all. Here, he saw the starting point for technology assessment, entirely in the spirit of the OTA. Accordingly, Braun defined characteristics of TA in Austria (and internationally), which are still influential today by emphasising the networking and mediation aspect of TA between different actors groups. He saw the research activities of TA as characterised by a wide variety of methods.

The following anecdote may have decided the fate of TA in Austria: An interviewee recalled how Heinz Fischer was fascinated by the OTA. He accompanied Federal President Kirchschläger to the USA in March 1984. At that time, Fischer was Minister for Science and Research and later became President of the Austrian National Council and Federal President. Inspired by the direct link between this qualified research and expert institution and Congress, he promoted efforts to establish a similar institution in Vienna (I07).

After a first high point in 1978 around the vote on the nuclear power plant in Zwentendorf (NOWOTNY 1979), resistance against technology rose again in Austria in 1984, when the occupation of the fluvial forest Hainburger Au aimed at preventing a river power plant in the later Donau-Auen National Park (PELINKA 1986). The perceived scepticism about technology prepared the ground for the emergence of the Green Movement. Later, this topic was often analysed and relativized at the ITA, especially in the context of the Eurobarometer projects on genetic engineering (see TORGERSEN/SEIFERT 1997 as the first ITA publication on this subject). The Austrian community hence established an independent, expert-oriented approach to dealing

ITA Archive, memoirs by Ernest Braun "The facts, from my point of view, which led to the unfortunate break between me and the ITA", 20.5.2005, p. 1. Archive of the TU Vienna, AT TUWA 4.Z. 4010/1984, Report of the Research Institute for Technology and Society of 22.11.1984 for submission/ report to the Senate, session of 14.1.1985.

4 Agreement on the establishment of a research institute "Technology and Society" at the TU Vienna, concluded between the TU Vienna and VÖI (Federation of Austrian Industry), p. 2f. (Annex A to the report of 22.11.1984 cited above) (translation by authors).

Fritz Paschke, among others, was initially assigned to the Institute (see the report of 22.11.1984, p. 3, quoted above).

manfredschmutzer.at/schmutzer.html (12.4.2018). 
with the effects of modern technology with three institutes: first, the ITG at the TU Vienna (1982, see above), followed a little later by technology assessment established at the Austrian Academy of Sciences (1985, see next section), and finally the Institute for Science and Technology Studies (STS) at the University of Vienna (1988). At the same time, several European countries established TA institutions linked to their parliaments during the 1980s (e.g. the Office parlementaire d'évaluation des choix scientifiques et technologiques/OPECST of the French Parliament, founded in 1983, the Rathenau Institute in 1986 in the Netherlands, the Parliamentary Office for Science and Technology (POST) in 1989 in Great Britain, or the Büro für Technikfolgenabschätzung beim Deutschen Bundestag/TAB, founded in 1990 in Germany) as were STS institutes at universities.

\subsection{THE ESTABLISHMENT OF THE WORKING GROUP TECHNOLOGY ASSESSMENT AT THE AUSTRIAN ACADEMY OF SCIENCES (1984/85)}

In 1984, at last, the Austrian Academy of Sciences became the centre of considerations for institutionalising TA in Austria. ${ }^{7}$ Initially, the actors considered founding the TA institute at an Austrian university, such as the TU Vienna. They discard this idea after the founding of the ITG in 1982. The ITG, however, was only made possible by the Igler-Foundation on a small scale and thus not interdisciplinary in a narrower sense. On the one hand, independence from technological development at technical universities spoke in favour of the Austrian Academy of Sciences. On the other hand, the broad, multidisciplinary environment still favours interdisciplinary work today. Besides, there was already one OeAW research institute (the Institute for Socio-Economics) that could expand in terms of both subject matter and methodology.

Discussions on the establishment of TA ultimately culminated in an official letter from the Research Section of the Federal Ministry of Science and Research in October 1984 to the then Secretary-General of the Austrian Academy of Sciences, Werner Welzig. In this letter, the Ministry informed of "the considerations [...] that have been made in recent days regarding the possible establishment of an Institute for Technology Assessment and Long-term Development at the Austrian Academy of Sciences" (translation and emphasis by authors $)^{8}$. This letter shows the support for an initial discussion paper on institutionalising $\mathrm{TA}^{9}$ by the responsible ministerial departments and people within the Academy from both divisions (including the statistician Gerhart Bruckmann and the electrical engineer Fritz Paschke). The OeAW Institute for Socioeconomic Development Research (ISOZÖK) hosted previous studies in technology assessment in the broader sense (particularly microelectronics and robotics). The actors wanted the ISOZÖK to supplement its previous sociological and economic work by specific TA studies with an interdisciplinary approach, including the natural and engineering sciences. Furthermore, TA should refrain from political statements and provide neutral expertise. Against this background, at Paschke's suggestion ${ }^{10}$, it was proposed to attach a working group on technology assessment to this institute - for economic and infrastructural reasons.

These efforts to institutionalise TA were accompanied by an inter- and transdisciplinary “Technology Assessment Project Team"11 $^{\prime 1}$ at the BMWF, chaired by the Research Section ${ }^{12}$. The team concretized the proposal of foreign experts on the establishment of $\mathrm{TA}^{13}$ at the National Day Symposium in Austria in 1984: from November 1984 onwards, this project team provided a forum for discussing the concept and orientation of the future institute and possible projects, and for providing advice

7 A first attempt in this direction was made by Helga Nowotny, the later founder of the Science and Technology Research Institute at the University of Vienna; in 1982/83 she held informal talks with the management of the OeAW, which, however, were going nowhere at the time (source: personal communication, 15.3.2018).

Archive of the OeAW: Technology Assessment/ISET. Letter from Norbert Roszenich to Werner Welzig, 24.10.1984.

9 Archive of the OeAW: Technology Assessment/ISET. Proposal for the establishment of an institute to study technology impacts and long-term developments. Supplement to the letter of the BMWF of 23.11.1984. Discussion paper on institutionalisation written by Ernest Braun, Helga Nowotny, then Professor of Science Research at the University of Vienna, and Ina Wagner, then Professor of Computer Science at the TU Vienna.

$10 \quad$ Ibid.

11 Officially: "Project Team Technology Assessment", as recorded in minutes of each meeting. Archive of the OeAW: Technology Assessment/ISET, short minutes of the constituent meeting of the technology assessment project team of 25.10.1984. Supplement to the letter of the BMWF of 23.11.1984.

12 Archive of the OeAW: Technology Assessment/ISET. Letter from Norbert Roszenich to Werner Welzig, 24.12.1984., Annex 2, file note, p.1. verbatim: "This [coordination of concepts with other ministries concerned, social partners, three parliamentary groups] can be carried out in the BMWF's 'TA' project team or in an evaluation procedure which ends with a subsequent report and request by the Federal Minister to the Council of Ministers"' (around February 1985).

13 Archive of the OeAW: Technology Assessment/ISET. Letter from Otto Meixner/BMWF to Hans Tuppy dated 3.10.1985. 
on how to establish such an institution ${ }^{14}$. This project group supported the recommendation to affiliate a TA working group at ISOZÖK under director Ernest Braun. ISOZÖK should continue to pursue "macroeconomic objectives [...] or the tasks of technology assessment taken over within the framework of the microelectronics promotion programme of the Federal Government"15 (own translation). In agreement with the social partners, the departments concerned, and scientific partner institutions, the project group set out to prepare the establishment of an Institute for Technology Assessment, together with an already informally existing working group. In particular, it was essential to ensure "sufficient freedom of action" for the institute ${ }^{16}$. The proposal for the working group on technology assessment intended basic funding by the BMWF and the establishment at the OeAW. This budget could only fund a small group of people; additional staff should join as affiliated fellows from other institutes or be paid by research funds. ${ }^{17}$ An internal OeAW advisory board was to support the institute's work, as was customary for all research institutions of the Academy at the time.

The Institute should make a "scientific contribution to the long-term socially beneficial application of technology", with the immediate objectives being both "the preparation of technology impact assessments and research in the field of technology policy" (own translation). Although the Institute would supervise individual technology impact assessments, external teams of scientists would prepare them; the funds would come from external public sources. ${ }^{18}$ The research itself should be interdisciplinary and include various issues, e.g. the methodology of TA and forecasting, technical innovation, history of technology, dynamics of technical and social developments or workplace design. ${ }^{19}$

At the beginning of 1985, the BMWF increasingly funded work on technology assessment under the research priority "microelectronics" (budgeted with one million Schilling ${ }^{20}$ ), in addition to the previous work of the ISOZÖK, which also carried out technology assessment funded by the OeAW (also one million Schilling). ${ }^{21}$ Through involvement in the above-mentioned 'priority area' of the BMWF and prior projects on "Microelectronics", "Industrial Robots in Austria", and "Flexible Automation", there was proximity between the planned technology assessment working group and the portfolio of ISOZÖK. The founders considered additional possibilities for cooperation related to other thematic priorities (such as the planned studies "Perspectives of technology and the world of work in Austria" and "EDP procurement as an instrument of state technology policy"). At the same time, further proposals dealt with considerations on the precautionary principle, the expansion of the transport concept and trade in "high technology", and the transfer of know-how, among other things. ${ }^{22}$

Subsequently, Ernest Braun submitted a statement to the BMWF on the relation to the OeAW and broadening its original concept to institutionalise technology assessment and research on long-term developments. He favoured institutionalising TA at the Academy, as he considered basic research necessary for technology assessment, while a thematically flexible group should work on interdisciplinary expert opinions. ${ }^{23}$ Braun saw technology assessments as a central task of the research unit aiming at a comprehensive description of the expected consequences of a technical project or the solution of a social problem related to technology. In doing so, he underlined the necessity to distinguish scientific principles from political decisions clearly. ${ }^{24}$

14 Archive of the OeAW: Technology Assessment/ISET. Brief minutes of the constituent meeting of the Technology Assessment Project Group of 25.10.1984. Supplement to the letter of the BMWF of 23.11.1984.

15 Brief minutes of the constituent meeting of the Technology Assessment Project Group of 25.10.1984. Supplement to the letter from the BMWF of 23.11.1984.

16 Archive of the OeAW: Technology Assessment/ISET. Brief minutes of the constituent meeting of the Technology Assessment Project Group of 25.10.1984, p. 2. Supplement to the letter of the BMWF of 23.11.1984.

17 In fact, from the beginning, there were TA researchers financed by third parties, but there was never a double affiliation of staff from other institutes or the Scholarly Society.

18 Such complete outsourcing of TA projects to external parties never occurred, all projects were and are still carried out by internal staff, often in cooperation with external experts.

19 Archive of the OeAW: Technology Assessment/ISET. Proposal for the establishment of an institute for the study of technology consequences and long-term developments, p. 1. Supplement to the letter of the BMWF dated 23.11.1984. While the history of technology and forecasting in a narrower sense never became subject of concrete projects, other topics have repeatedly become part of the work programme.

20 This corresponds to approximately 143,000 EUR of purchasing power at the time.

21 Archive of the OeAW: Technology Assessment/ISET. Exchange of letters between the General Secretariat of the OeAW and Ernest Braun, 16.1.1985.

22 Archive of the OeAW: Technology Assessment/ISET. Preliminary minutes of the 26th meeting of the board of trustees of the Institute for SocioEconomic Development Research (29.3.1985) of 2.4.1985. See section 3.1for an overview of the projects actually implemented during this period.

23 Archive of the OeAW: Technology Assessment/ISET. Thoughts on founding an institute (or research unit) for technology assessment and futurology at the Austrian Academy of Sciences. Supplement to letter from Ernest Braun to BMWF of 10.4.1985.

24 Ibid. 
Braun proposed the initiation of projects both by clients and by staff members themselves, but always in an agreement between the scientific advisory board and the institute's management. The respective decisions should pay attention to both the financial feasibility and the interests of political institutions. Both the actuality of the topics and the research work's independence were vital to him. Against this background, he proposed to consider the possibility of third-party funding. ${ }^{25}$ Organizationally, the working group would consist of a semi-flexible structure of experts and consultants in an interdisciplinary composition. Additionally, if necessary, the TA team should consider the opinions of interested groups (in the sense of transdisciplinary research approaches). Basic research should be carried out by permanent staff and in cooperation with interested scientists from other institutions (e.g. fellows, freelance volunteers). The focal points of the research activities were not finally defined; however, three topics seemed particularly relevant at that time, favoured in various cooperations: (1) "Technology assessment, technology and the world of work, (2) fundamental questions of the links between scientific research and technical innovation, and (3) questions of selecting and promoting scientific research in a small country" (translated by authors). ${ }^{26}$

Additionally, establishing a "National Committee for Technology Assessment"27 was widely welcomed, chaired by the Minister of Science, as an additional body "to bring social partners, relevant ministries and other economic and social institutions closer to relevant research in the field of technology assessment". ${ }^{28}$ As contact point for TA in Austria, this committee was supposed to indicate technology-related tendencies and consequences to political decision-makers and the general public, give suggestions for projects, review the quality of technology assessment, and integrate the results into the political decision-making process.

"All institutions in Austria dealing with technology assessment and technology evaluation should report to this National Committee at least once a year on their work and receive recommendations for future investigations or support the National Committee in its work beyond that." 29 (own translation)

The Council of Ministers finally adopted this proposal in July 1985 as "Beirat für Technologiebewertung" ("Advisory Council for Technology Assessment", translation by authors)..$^{30}$ Thus, establishing technology assessment in Austria gained momentum: In May 1985, the Federal Minister proposed the Council of Ministers to establish a TA Institute. ${ }^{31}$ This proposal addressed scientific, interdisciplinary research and practical preparation of decisions on promotion and regulation of technologies. Eventually, it even argued for advancing approaches in advising policy-makers: "Scientific advice by individual experts should gradually be replaced by interdisciplinary advice for complex interdisciplinary questions" (translated by authors). ${ }^{32}$ Furthermore, the proposal particularly emphasised the independence and scientific objectivity of the OeAW. ${ }^{33}$ The institute should focus on the Austrian specifics of the political and scientific landscape. ${ }^{34}$

25 This illustrates a typical dilemma of TA financing that can also be observed internationally: external financing can mean, on the one hand, that the scope of action is extended beyond that provided by the basic financing, i.e. more topics can be covered or more addressees can be reached. In addition, external clients are also a certain guarantee of topicality and political or social need. On the other hand, the orientation towards external needs can represent a certain restriction of independence, for example by orienting the topics or questions too much towards concrete interests of the counsellors. Always excluded, not only for scientific TA as it is conducted at the OeAW until today, but also in international comparison, is any kind of direct influence on the study results themselves. This is ensured by an explicit separation of TA studies with recommendations for action from a TA point of view on the one hand, and the subsequent political processes with possible decision-making on the other, and corresponds to the internalised ethos of TA practitioners.

26 Archive of the OeAW: Technology Assessment/ISET. Reflections on the foundation of an institute (or research unit) for technology assessment and futurology at the Austrian Academy of Sciences, p. 6f. Supplement to letter from Ernest Braun to BMWF of 10.4.1985.

27 Established in 1985 under the name "Council for Technology Assessment" chaired by the BMWF (see 2.6); see also RAKOS (1988, 205f.) who describes this Council as non-functional, possibly because of lack of political interest and the lack of high ranking members of the board".

28 Archive of the OeAW: Technology Assessment/ISET. Short minutes of the meeting of the project teams Technology Assessment of 19.4.1985, p. 2. Supplement to the letter of the BMWF of 26.4.1985.

29 Archive of the OeAW: Technology Assessment/ISET. Report and proposal to the Council of Ministers Technology Assessment/Technology Assessment". Proposal for the establishment of an Advisory Council for Technology Assessment" (2.7.1985), p. 4/5. Supplement to the letter of Norbert Rozsenich, 29.7.1985.

30 Precise date: 16.7.1985. Archive of the OeAW: Technology Assessment/ISET. Letter from Norbert Rozsenich dated 29.7.1985.

31 Archive of the OeAW: Technology Assessment/ISET. Letter from Norbert Rozsenich to Werner Welzig dated 14.5.1985.

32 Archive of the OeAW: Technology Assessment/ISET. Report and proposal to the Council of Ministers Technology Assessment. Proposal for the establishment of an Advisory Council for Technology Assessment" (2.7.1985), p. 2. Supplement to the letter from Norbert Rozsenich, 29.7.1985.

33 Ibid., p.3.

$34 \quad$ Ibid., p.4 
The OeAW's presiding committee welcomed this political initiative - from 1985, Hans Tuppy, who later became Minister of Science, was president, while Werner Welzig continued to serve as secretary-general. On 21 June $1985^{35}$, the OeAW officially affiliated the Working Group on Technology Assessment to ISOZÖK and renamed the research institution "Institute for Socioeconomic Development Research and Technology Assessment (ISET)". Ernest Braun became head of the working group on technology assessment. The former director, Robert H. Reichardt, eventually handed over the management of the institute to Ernest Braun. Peter Fleissner remained as deputy director (I02) as he had previously held this position at ISOZÖK. As planned, increasing the already existing budget item ensured financing: 'The planned basic budget of ATS 3 million' 36 was to be achieved by increasing the budget item 'Technology Assessment' (currently ATS 1 million) ${ }^{37}$ part of the Austrian Academy of Sciences' budget line, which was already provided for in the Federal Finance Act 1985." (translated by authors) ${ }^{38}$

Immediately after its foundation, the OeAW and the Federal Ministry of Economics and Technology organised a session on "Technology Evaluation - Technology Assessment" (translated by authors) at the European Forum Alpbach in August 1985.39 TA shared its first offices at the Austrian Academy of Sciences with the ISET socio-economic working group in an old flat in the Fleischmarkt in Vienna's $1^{\text {st }}$ district (cf. Table 4).

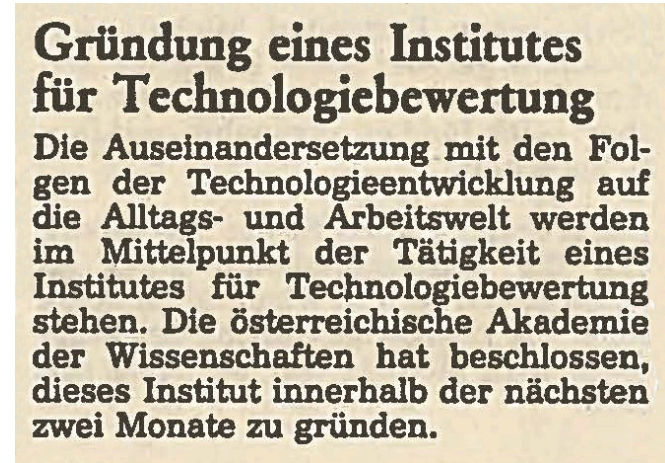

Figure 1: Founding notice in the Wiener Zeitung of May 23, 1985

35 Archive of the ITA: minutes of the general meeting of the Austrian Academy of Sciences of 21.6.1985.

36 This corresponds to approximately 429,000 EUR of purchasing power at that time.

37 This corresponds to approximately 143,000 EUR of purchasing power at the time.

38 Archive of the OeAW: Technology Assessment/ISET. Report and proposal to the Council of Ministers Technology Assessment/Technology Assessment". Proposal for the establishment of an Advisory Council for Technology Assessment" (2.7.1985), p. 3. Supplement to the letter from Norbert Rozsenich of 29.7.1985.

39 Archive of the OeAW: Technology Assessment/ISET. Letter from Norbert Rozsenich dated 29.7.1985. 


\subsection{CONFLICTUAL YEARS AS A WORKING GROUP TECHNOLOGY ASSESSMENT AT ISET (1985-1987)}

Thus, the TA's institutionalisation at the Academy of Sciences was completed for the time being by mid-1985. ${ }^{40}$ The way of establishing TA at the Austrian Academy of Sciences - as a working group docked to an existing institute - may be interpreted as a successful political compromise between politicians (the establishment of a TA institute) and the Academy's management (no new additional organizational unit). However, within the institute, this externally decided affiliation to an existing research institution, including installing a new director, posed significant challenges in the medium term. Although Ernest Braun may have been initially enthusiastic about Peter Fleissner's critical work (I12), incompatibilities in working methods, communication culture and, above all, the different approaches to science soon became apparent. While Fleissner's group carried out socially committed (emancipatory) critical social research ${ }^{41}$, Braun wanted to establish TA as "distanced" as possible according to international models.

Additionally, conflicts in management style became apparent, rooted in the gap between the traditionally flat-hierarchical former ISOZÖK ${ }^{42}$ and the Austrian Academy of Sciences' top-down decision. ${ }^{43}$ These differences and conflicts between the two parts of the ISET ultimately led to irreconcilable divergences (as some interviewees confirmed; I01, I02, I04, I06) and to the final break between the two factions Braun and Fleissner, while discrepancies in content (I03, I06) and working methods may also have played a role. As far as can be seen from the published research reports, there was only occasional cooperation between the two parts of the institute in these first years. Nevertheless, these were productive years, as a glance at the list of project reports produced shows (see section 3.1).

Nevertheless, political support for technology assessment remained unbroken during these years. In the technology focus on microelectronics (1984-1987), for example, TA was promoted as an approach of socio-scientific accompanying research for participatory market launch strategies and analyses of acceptance ${ }^{44}$ as one of ten focal points of the BMWF's funding programme. The activity report of the Research Section of the BMWF 1983-1986 highlighted the extension of ISOZÖK by the Working Group on Technology Assessment. ${ }^{45}$

Against this conflictual background, the idea of an independent institute for TA was promoted, especially by Braun. His efforts were finally crowned with success: on November 6, 1987, the general assembly of the OeAW decided to set up a separate Commission for Technology Assessment at the Academy. Barely one month later, on December 11, 1987, the Academy transformed the Commission into the Technology Assessment Unit (TAU). ${ }^{46}$ The TAU's initial term was January 1, 1988, to December 31, 1990, and its director was Ernest Braun. ${ }^{47}$ Thus, TA in Austria was established as an independent research institution of the Austrian Academy of Sciences on December 11, 1987. The former ISOZÖK became the "Institute for Socioeconomic Development Research (ISEF)" under the leadership of director Wolf-Dieter Grossmann ${ }^{48}$ (see Figure 1). The Academy split the TA funds in a 2:1 ratio (TAU:ISEF). Despite the agreement that any future increase in the budget should only benefit the TAU, Braun felt that the distribution was inappropriate (I05).

40 Archive of the OeAW: FE files, socio-economics, 1/1 st newspaper report on the establishment of an institute for technology assessment. Wiener Zeitung, 23.5.1985.

41 In the words of Peter Fleissner: my interest in socialism, of which I made no secret even in scientific television programmes (some of them in Eurovision)" (translation by authors), see homepage text Curriculum Vitae - Wissenschaftlich-menschlicher Werdegang" , February 2002, peter.fleissner.org/homepage/default.htm (13.4.3018)

42 In the words of Peter Fleissner: The Institute grew, and with it the grassroots democracy, which I still consider the best form of organisation in small institutions", ibid (translation by authors).

43 In addition to the above-mentioned content points regarding orientation and working methods, there were apparently also personal animosities between Braun and Fleissner, see ITA-Archive, Erinnerungen von Ernest Braun, 20.5.2005, p. 1-2.

44 Archive of the OeAW: Technology Assessment/ISET. Technologieschwerpunkt Mikroelektronik Förderungsprogramm 1984-1987, BMWF, Section Research, p. 10.

45 Archive of the OeAW: Technology Assessment/ISET. Activity Report of the Research Section of the BMWF 1983-1986, p. 12.

46 In German, the research unit was called Forschungsstelle für Technikbewertung", abbreviated FTB.

47 Archive ITA: extract of the minutes of the general meeting of the Academy on 11.12.1987.

48 Archive of the OeAW: archival aid FE files socio-economy. 

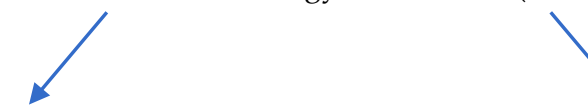

Development Research (ISEF)

Commission for Technology

Assessment

1988

1991

1994

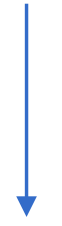

Research Unit for

Socioeconomics

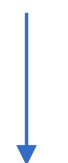

Institute for Technology

Research Unit for

Ecosystem and Environmental

Studies (until 1995)

Technology Assessment

Unit (TAU/FTB)

Assessment (ITA)

1998 Research Unit for Institutional

Change and European Integration (IWE)

2004 - Work Area of Media and Technology

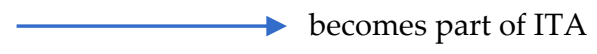

- Work Area Migration Research Unit

- Work Area

European Studies

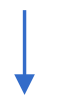

Commission for

Migration and

Integration Research

Institute for European

Integration Research (EIF)

2006

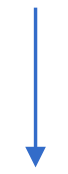

- Work area HTA

now attached to LBG

2012 now attached to the University of Vienna

2018

Figure 2: The OeAW research institutions regarding TA 1971 to 2018 


\subsection{EARLY YEARS AS A RESEARCH UNIT (1988-1991): ESTABLISHMENT UNDER FINANCIAL AND INSTITUTIONAL UNCERTAINTY}

The establishment of an independent research unit also fuelled the development of an independent portfolio as a research and advisory institution. In these first years, the number of scientific staff increased significantly. Braun's active personnel policy aimed at expanding the range of topics beyond the initial focus on telecommunications technologies to create a general TA institute. With the recruitment of two economists, a sociologist, a communication scientist, a lawyer and two biologists in addition to two physicists and a lawyer-political scientist - the research portfolio expanded towards biotechnology, environment, and medicine. The disciplinary growth and intensive cooperation led to the subsequent development of interdisciplinary competence at the Institute. The increase in personnel also made it necessary to enlarge the office space. In the short term, the TAU rented an additional location in Czerningasse in the $2^{\text {nd }}$ district in Vienna, and from 1990 it moved to the OeAW Institute building in Postgasse in the $1^{\text {st }}$ district, where the Institute then resided for almost ten years (see Table 4 and Figure 3 ).

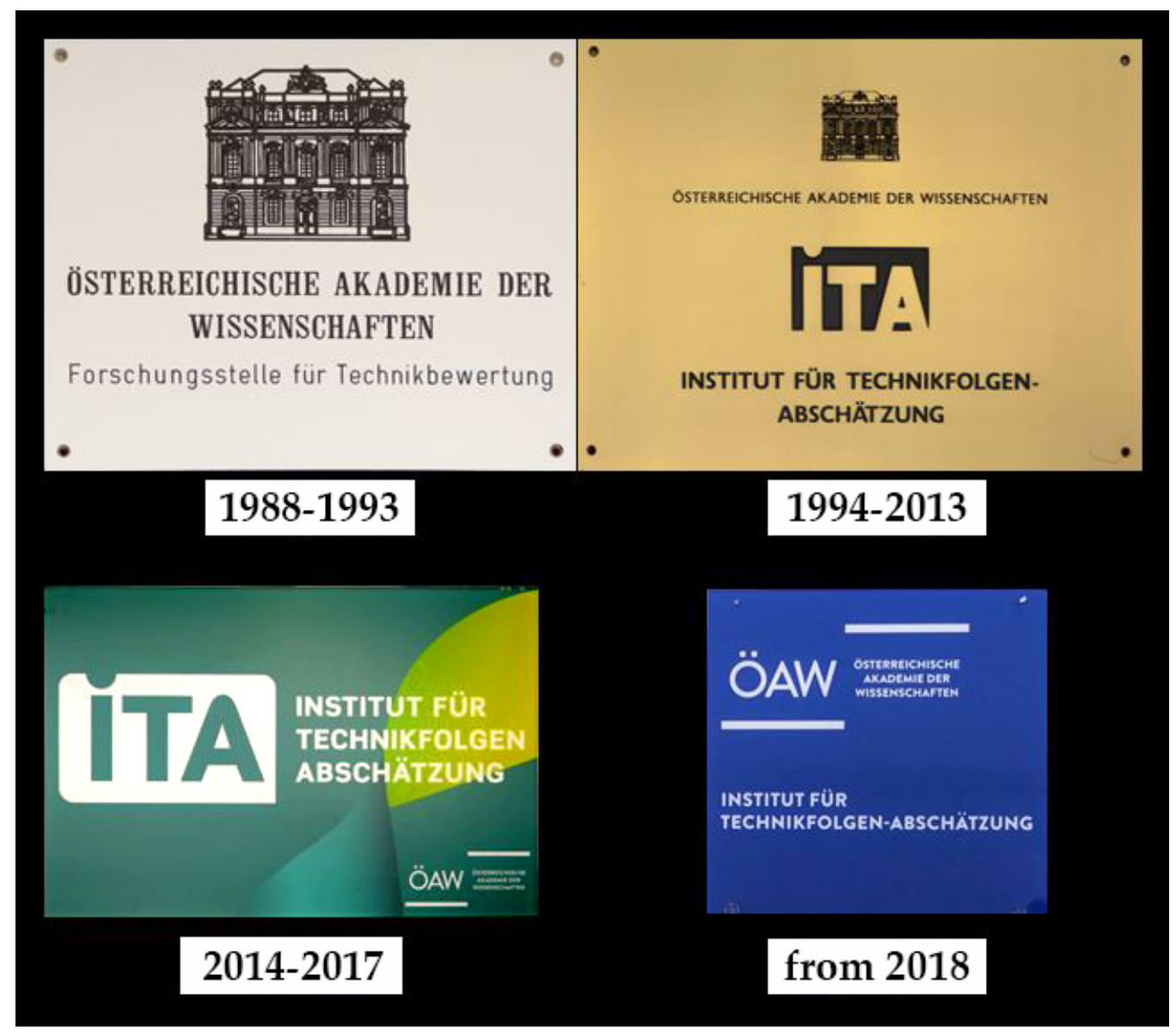

Figure 3: The first door sign of the TAU and following door signs of the ITA (Photos: W. Peissl) 
Braun envisaged a more substantial adoption of the OTA model ${ }^{49}$ with a closer link between the research unit and Austria's political agenda. The Institute already received its first mandate by Parliament in spring 1990 (see section 3.2). However, financially speaking, the TAU could not achieve independence, as its political financing mechanisms did not consider the latest developments. The distribution of BMWF funds between the ISEF and TAU was not resolved satisfactorily from the TAU's perspective. The establishment of TA as a separate research unit had triggered the discussion anew ${ }^{50}$ as only activities for the parliament were attributed to the TAU alone..$^{51}$ Braun pleaded for converting the TAU into an institute to maintain personnel continuity, a demand that the TAU advisory board, although generally benevolent, again, tied to a "secure and sufficient budget" 52 . Clarifying the institutional situation became more and more urgent for the unit's staff; with reference to international standards, they argued for transforming the unit into an institute. ${ }^{53}$ The OeAW flatly rejected a redistribution of funds between ISEF and TAU ${ }^{54}$, arguing that the federal budget had not explicitly been created for the latter. Additionally, it argued that the research unit held no monopoly on TA in Austria. The foundation as a research unit formally secured the research area "technology assessment" at the OeAW for a limited period of three years ${ }^{55}$. However, there was no financial security beyond that until April 1990. ${ }^{56}$ Ernest Braun's frustration with the bureaucratic procedures at the Academy ultimately led to his resignation as head of the research unit, which meant that a (renewed) consolidation with the ISEF was possible. In one of his last letters, Braun vehemently opposed this idea, both for personal and content-related reasons ${ }^{57}$, as did the staff of the TAU: eventually, the same reservations as at the time of the separation in 1987, i.e. lack of compatibility of approaches, remained.

In addition to personal commitment ${ }^{58}$, Braun tried to secure the research unit's independence through international advocates. ${ }^{59}$ The emerging hierarchical decision-making process regarding the continuation of the TAU conflicted with a flat hierarchical communication culture, which had been promoted in the young TAU by the interdisciplinary working method. The ability to compromise on the part of the presiding committee of the OeAW and a diplomatic balancing act of the TAU staff between the demand for information on the one hand and the right to have a say on the other hand ${ }^{60}$ ultimately enabled a constructive dialogue (I05). Discussing the TAU's future, Braun also referred to a conflict between the Academy and the ISEF $^{61}$. In this light, he chided the privileged treatment of the ISEF by the Academy in the form of higher basic funding and half of the budget for technology assessment; once more, he argued against a merger. ${ }^{62}$ Finally, in October 1990, the research unit was ensured three more years (1991-1993). ${ }^{63}$ Braun and Paschke proposed the Graz economist Gunther Tichy as the new director of the TAU. Tichy agreed under the condition that the OeAW transforms the research unit into an institute, that it would receive sufficient basic funding, and that the OeAW redistribute the respective TA funds. ${ }^{64}$

49 Archive of the OeAW: FTB. Minutes of the advisory board meeting of the Technology Assessment Unit of 26.4.1989.

50 Ibid.

51 Archive of the OeAW: FTB. Preliminary minutes of the $2^{\text {nd }}$ advisory board meeting of the Technology Assessment Unit 18.12 .1989 (minutes corr. 15.1.1990), p. 3 .

52 Ibid.

53 Archive of the OeAW: FTB. Letter from the staff of the Research Unit Technology Assessment to the Presiding Committee of the Austrian Academy of Sciences, 11.1.1990.

54 Archive of the OeAW: FTB. Letter from Werner Welzig to Ernest Braun dated 15.1.1990.

55 At that time, research posts were limited to three years with the possibility of a one-off extension, i.e. until the end of 1990 or the end of 1993.

Advisory board meeting 3.4.1990.

Archive of the OeAW: FTB. Letter from Ernest Braun to the Presiding committee of the Austrian Academy of Sciences, 4.5.1990, p. 1.

Archive of the OeAW: FTB. Letter from Werner Welzig to Ernest Braun of 9.8.1990 with reference to his letter of 20.7.1990.

59 See e.g. letter of the then head of the Department of Applied Systems Analysis at the Nuclear Research Centre Karlsruhe (later ITAS), Herbert Paschen, to the Presiding Committee of the Austrian Academy of Sciences. Archive of the OeAW: FTB. Letter of 14.8.1990.

60 Archive of the OeAW: FTB. Letter from the staff of the Technology Assessment Unit to the Presiding Committee of the OeAW/General Secretary Werner Welzig, 14.8.1990.

61 This reference refers to the temporary closure of the ISEF by the State Police at the beginning of 1991, on the grounds that the ISEF was using equipment to print Communist leaflets. This accusation led to labour court cases and even to immediate dismissals. The OeAW finally lost the process, apologised and reversed the dismissals (I02, I04). Archive of the OeAW: in the archive auxiliary Socio-economics you can find the following: After the employees of the institute were accused of embezzlement and the use of the institute's computers for the production of illegal leaflets in autumn 1990, the work of the institute was stopped shortly afterwards. (S. 1, translated by authors) See also the view of Peter Fleissner in his homepage text Curriculum Vitae Scientific-human career", February 2002, peter.fleissner.org/homepage/default.htm (13.4.3018): In 1990, the Austrian State Police came with four armed men to the temporarily closed institute and had the hard disks examined for the keywords 'green', 'socialist' and 'communist', in the erroneous opinion that the Academy Institute would infiltrate the peace movement in Western Europe under communist rule. Even the printers were confiscated" (translated by authors).

62 Archive of the OeAW: FTB. Letter from Ernest Braun to the Presiding Committee, 24.9.1990.

63 In an extraordinary advisory board meeting on October 2, 1990, the further development of TAU, which was scheduled for the end of 1990, was discussed. Until then there was no official assurance of a continuation.

64 Archive of the OeAW: FTB. Preliminary minutes of the $4^{\text {th }}$ (extraordinary) advisory board meeting of the Technology Assessment Unit, 2.10 .1990$, p. 2. 
For the transitional period between Braun's final return to England in mid-199165 and Tichy's entry at TAU, staff member Walter Peissl served as managing director of the Technology Assessment Unit. In retrospect, we understand these months of “interregnum" between Braun's informal departure (in November 1990) and Tichy's entry (in November 1991) as an institutional breakpoint. On the one hand, the unbroken political support of the BMWF in the background, on the other hand, activities of the TAU staff, prevented the shutdown of the TAU. These months had a significant impact on the staff at that time especially Johann Čas, Markus Mikl, Michael Nentwich, Walter Peissl, Paul Pisjak, Christian Rakos, Helge Torgersen, and Claudia Wild (in alphabetical order). In numerous internal retreats between autumn 1990 and spring 1991, this core group intensively discussed the purpose and justification of TA in general and the orientation of TAU in particular. The resulting (more or less) consensual positioning of the research unit between the two poles of science and policy advice - or thematic specialisation and broad openness regarding public participation, the typical scale of TA studies, the institutional anchoring of TA in Austria and the organisation of external relations of the research unit ${ }^{66}$ laid a solid intellectual basis for the following years of development. Gunther Tichy's assumption of office on November 11, 1991, marked the end of the "interregnum" of the research unit and heralded a new chapter in the history of the institute.

\subsection{DEVELOPING THE SCIENTIFIC BASE AND EVALUATION: FROM RESEARCH UNIT TO INSTITUTE (1991-1994)}

With the establishment and financial support as a research unit at the Austrian Academy of Sciences for two three-year periods, TA in Austria had defined its basic working methods and orientation between scientific research and policy advice. The phase that followed was characterised by diversification and professionalisation of the research field (I05).

Gunther Tichy's appointment as head of the research unit did not bring about any fundamental changes regarding the TAU's work but focused on the continuity and stability of the institution. From the outset, he pleaded to retain the work programme and style of the research unit and increase the proportion of basic research in relation to contract research as the TAU was part of a research institution. ${ }^{67}$ Tichy successively implemented his strategy of professionalisation as a scientific institute. From then on, the team routinely planned scientific publications in addition to research reports. Besides, the institute organised a conference series (from 2001), a grey publication series (from 2002), and published a monograph on TA in Austria (Tichy 2004).

Tichy's membership in the scholarly society OeAW (1987 corresponding member, 1994 real member ${ }^{68}$ ) was interpreted as internal support and strengthening this particular research unit (I05). However, the problem of insufficient funding remained a virulent one, especially in the context of policy advice activities and capacity building on relevant topics. ${ }^{69}$ With a view to long-term networking and cooperation, the research unit also needed to ensure continuity among the staff as an "Institute for Technology Assessment"70 - a positively evaluated request linked to the usual procedure of the Academy: a comparative evaluation with corresponding institutions. ${ }^{71}$ This procedure strengthened the claim to establish the research field of TA in the Austrian scientific landscape long term, although this evaluation was to take more than a year.

Within the TAU, the team advanced its thematic diversification even further, a process which had already begun under Braun's leadership. Regarding the advisory mandate, the TAU strengthened the direct applicability for the policy context. These years showed the first time the TAU gave parliamentary policy advice in addition to scientific project work. The parliamentary com-

65 After his engagement in Austria, Ernest Braun spent several more years as a visiting professor at the Open University in Milton Keynes/Great Britain (until 1994). He died in Austria at the age of 89 in 2015.

66 See ITA archive: internal minutes of meetings, autumn 1990 - spring 1991.

67 Archive of the OeAW: FTB. Minutes of the autumn advisory board meeting of the Technology Assessment Unit of the Austrian Academy of Sciences, 13.12.1991.

68 See Almanac of the OeAW 2011. Gunther Tichy resigned his membership in 2012 due to differences of opinion with the Presiding committee regarding the governance of the Academy (TASCHWER 2012).

69 Archive of the OeAW: FTB. Minutes of the autumn advisory board meeting of the Technology Assessment Unit of the Austrian Academy of Sciences, 13.12.1991.

70 Archive of the OeAW: FTB. Letter from Gunther Tichy to the Presiding committee of the Austrian Academy of Sciences, 13.10 .1992$.

71 Archive of the OeAW: FTB. Letter from Karl Schlögl to Gunther Tichy dated 27.10.1992. 
mission of enquiry on genetic engineering entrusted the TAU with its leadership..$^{72}$ The research unit participated in the preparations and meetings, summarizing expert reports and taking minutes. It prepared a comprehensive expert report in which it presented the essential questions on genetic engineering expanding beyond monodisciplinary discussions. While the TAU initially perceived the cooperation as a breakthrough for establishing parliamentary TA in Austria, it was not continued beyond the work within the commission of enquiry for the time being (for details, see section 3.2).

After persuasion and contrasting the cameralistic accounting that had been common at the Austrian Academy of Sciences at the time, the TAU director and the Academy's central administration agreed to set aside reserves from third-party funds to secure employment contracts ${ }^{73}$. Subsequently, this arrangement enabled the TAU to operate relatively autonomously. For the first time, the TAU was thus able to carry out studies and develop thematic foci it itself deemed relevant. This development was the first step towards differentiation of TA in Austria regarding topics and scientific deepening. The ITA - as, incidentally, other institutes of the OeAW - still can build up such reserves to form an autonomous research portfolio and to compensate for short-term financial bottlenecks. The advisory board also supported institutional continuity. ${ }^{74}$ However, the tight budget again forced Tichy to file a proposal to reform the organisational structure and accounting system regarding thirdparty funding in February 1993. He anticipated general problems for third-party funded research bodies and institutes if its proportion in research would increase further. ${ }^{75,76}$ In the case of the TAU, this was solved by creating a reserve fund (with the target size of approximately one employee's annual salary). ${ }^{77}$

The entire advisory board unanimously supported institutional continuity of the research unit for TA at the autumn meeting of the TAU on November $8,1993^{78}$ - subject to the results of the obligatory evaluation. Thus, the board initiated the transformation of the TAU into an institute.

Finally, in December 1993, the first external evaluation of the Technology Assessment Unit was concluded positively (see Table 1). The principal evaluator was Fulvio Caccia, a former member of parliament and president of TA Swiss, the Swiss national technology assessment institution. His evaluation report supports to end of the precarious situation of the TAU but criticises the lack of an integrative mission statement for the TAU. ${ }^{79}$ The following steps towards the consolidation of activities should be selecting research priorities to develop specific expertise. Due to its scientific orientation, an Austrian TA institute's function should not be limited exclusively to a so-called TA secretariat of a political unit. However, this was considered necessary for the legitimacy of the TAU or for strengthening TA to a certain extent. Nevertheless, he considered it essential to prevent such activities from consuming the resources of the TAU as its reputation was primarily based on scientific work. The evaluator praised the commitment to international networks above all. ${ }^{80}$

72 Archive of the OeAW: FTB. Preliminary minutes of the autumn advisory board meeting of the Assessment Unit of the Austrian Academy of Sciences on 9.11.1992.

73 Gunther Tichy, in a letter to Secretary General Schlögl, had suggested various options for being able to provide additional policy advice: the use of (part of the) third-party funds for medium-term employment contracts; the creation of a reserve to the extent of one person's annual salary from third-party funds in connection with a new form of employment contract (linked to third-party funds instead of project durations); or a reduction in the share of third-party funds in TAU from 50\% to 20\%. Archive of the OeAW: letter from Tichy, Gunther to Karl Schlögl, 16.4 .1992$.

74 Archive of the OeAW: FTB. Preliminary minutes of the autumn advisory board meeting of the Technology Assessment Unit of the Austrian Academy of Sciences, 9.11.1992, p. 4.

75 To take account of this development, Tichy proposed the following structure: academy projects (basically financed), joint projects (in which financiers might be interested) and pure third-party-funded projects (pre-financed by the Academy with the problem of uncertainty of financing).

76 Further proposals to reform the organisational structure and accounting system regarding third-party funding were made in February 1993 Archive of the OeAW: FTB. Letter from Gunther Tichy to Secretary General Karl Schlögl of 22.2.1993.

77 Archive of the OeAW: FTB. Preliminary minutes of the autumn advisory board meeting of the Technology Assessment Unit of the Austrian Academy of Sciences of 8.11.1993.

78 Ibid.

79 Authors' translation from the French original: [...] in the absence of a precise identity of the TAU, where different and partly incompatible types of activities coexist; this is a completely normal situation in the phase of setting up a new institution, but one that may create difficulties in the future. Archiv der OeAW: FTB. Forschungsstelle für Technikbewertung. An Evaluation by Fulvio Caccia and Benedetto Lepori, Section 5: Conclusions and recommendations.

$80 \quad$ Ibid. 
Table 1: Evaluations of TA at the Austrian Academy of Sciences

\begin{tabular}{r|l|l|l}
\hline Date & Institute & \multicolumn{1}{c|}{ Evaluators } & \multicolumn{1}{c}{ Result } \\
\hline $\mathbf{1 9 9 3}$ & TAU & F. Caccia, B. Lepori & Conversion into a (permanent) institution \\
\hline $\mathbf{2 0 0 3}$ & ITA & $\begin{array}{l}\text { K.U. Mayer (chair), J. Friedrichs, } \\
\text { J. von Hagen, R. Lesthaeghe, O. Renn }\end{array}$ & $\begin{array}{l}\text { Reorientation of the Environmental Technologies Department; the } \\
\text { takeover of the Media Department of the IWE; subsequently spin-off } \\
\text { of the HTA Department }\end{array}$ \\
\hline $\mathbf{2 0 1 1}$ & ITA & $\begin{array}{l}\text { D. Foray (chair), M. Bourrier, } \\
\text { B. Krings }\end{array}$ & $\begin{array}{l}\text { Strengthening the dual focus on scientific TA and policy advice and } \\
\text { cooperation with universities }\end{array}$ \\
\hline $\mathbf{2 0 1 8}$ & ITA & K. Konrad (chair), C. Büscher, I. Schneider & Supporting ITA's excellent development, adding strategic suggestions \\
\hline
\end{tabular}

The results of this evaluation not only confirmed the success of the activities undertaken until then but also prescribed the future (and still) dual-task of TA (namely research and advice). Immediately after the evaluation, the general assembly of the OeAW completed the transformation into the Institute of Technology Assessment (ITA) ${ }^{81}$ by acknowledging it and setting January 1,1994 , as the date. ${ }^{82}$

\subsection{DIVERSIFICATION AND CONSOLIDATION OF TA IN AUSTRIA: THE FIRST DECADE AS A RESEARCH INSTITUTE (1994-2005)}

With the transformation into an institute at the Austrian Academy of Sciences, technology assessment had arrived in the scientific research landscape of Austria in the long term. For the former TAU, this also marked the beginning of a period of peaceful development. Under the leadership of Gunther Tichy, the ITA was able to consolidate further. Besides, the Institute benefited from Tichy's practical experience as an established policy advisor, which contributed to the professionalisation of this aspect of the institute's work (I05; see also Nentwich/Peissl 2005).

The development of active interdisciplinary scientific research, especially towards the European Commission, also reinforced existing trends. Research in projects for the EC or EU had already been one of the TA working group tasks initially (the EU project on broadband communication was the first project completed). The increasing orientation towards Europe-wide networked research led to a considerable time expenditure - discussed several times. ${ }^{83}$ Established priorities of work remained. The focus was not only on a respective scientific professionalisation and profiling but also on better coordination and more robust integration between the respective fields. While the original focus of the TAU was in the field of ICT, the team soon supplemented this focus with projects on genetic engineering, medicine, and the environment in spring 1990.

The increased internationalisation and activity in TA-specific networks (European Parliamentary Technology Assessment EPTA, Network Technology Assessment - NTA) indicate that the ITA had established itself as part of the TA research field in Austria, the European, and the German-speaking countries. ${ }^{84}$ To this day, the ITA is an active part of both networks (see section 3.3).

81 Side note on the German names Forschungsstelle für Technikbewertung" and Institut für Technikfolgenabschätzung": The contemporary witnesses interviewed at the Institute reported that the original use of the (German) term Technikbewertung" had come about at Braun's wish. To Braun, socialised in the English-speaking world, the translation of assessment" with Abschätzung" did not seem adequate. Tichy was not happy with the term Abschätzung" either and favoured Analyse" to keep the abbreviation TA". In the end, the Institute's staff won through with their proposal to change the term Bewertung", which is normatively charged in German, to Folgenabschätzung". This is also in line with the international trend: internationally, the term technology assessment" or evaluation des choix technologiques" is common and is translated to German either as Technik-" or as Technologie-Folgenabschätzung".

82 Archive of the ITA: decision was taken on 17.12.1993 according to the minutes of the general assembly of the Austrian Academy of Sciences.

83 Archive of the OeAW: ITA. Minutes of the meeting of the advisory board of the Institute of Technology Assessment of the Austrian Academy of Sciences, 20.3.1995.

84 The EPTA network (eptanetwork.org) was founded in 1992 (NENTWICH 2016) - the TAU participated as observer or associated member from 1993 on - the network NTA (openta.net/netzwerk-ta) in 2004 (PEISSL 2004) - here the ITA was co-initiator and founding member. 
The mid-1990s - after intensive cooperation with Parliament 1990-1992 - represent another highlight of the policy advice activities by the ITA. However, this time the ITA directed its activities towards the Austrian administration. The implementation of the Technology Delphi Austria (1996-1998) on behalf of the BMWF not only contributed to a robust internal integration (all staff members of the institute were involved) but also finally established the ITA as a contact point in policy advice from the ministry's point of view (I07). The Technology Delphi was the first systematic technology foresight programme for Austrian decision-makers (Tichy 2001; Aichholzer 2001). Thus, the ITA finally arrived "in the serious analysis of complex issues" (I06, translation by authors). Simultaneously, we interpret the Technology Delphi as an essential step for Austrian TA: the systematic involvement of stakeholders illustrates the development from an expert-based to a broader understanding of TA. From ITA's point of view, the Technology Delphi thus represented a striking step towards increasing professionalisation and external perception of the institute - both in the political environment in Austria and the international academic environment (I05). Also, it allowed for developing new competencies within the institute, especially in cooperation with diverse groups of actors.

The interest in the ITA's Technology Delphi and its results may also be rooted in changes in the political environment. From the mid-1990s onwards, research policy changed to the extent that the BMWF was no longer the sole sponsor of the ITA. By the early 2000s, research and technology policy agendas gradually migrated from the Ministry of Science and Research to other actors. For the ITA, this meant a change regarding the primary political contacts in the administration (Tichy 2004).

While the competences concerning funding policy remained divided between various ministries (to this day), the "Advisory Council for Technology Assessment" 85,86 chaired by the Federal Ministry of Science and Research (later: Science and Transport), can be seen as an attempt to bundle technology policy and technology assessment. This advisory council resulted from proposals made by the "Technology Assessment Project Team" at the BMWF, which had institutionalised the project in 1984/85 (see Section 2.2 above). The ISET's technology assessment working group was present in the Council. However, due to a lack of political members, the Council was not effective (Rakos 1988, 206) and was replaced in 1988 by the "Council for Technology Development" 87 , also chaired by the Minister. This new Council now included parliamentarians and representatives of other ministries, thus better ensuring political links. The TAU, as well as the ITA from 1994 onwards, were a member of the Council. They were without voting rights and provided the scientific secretariat of the Council in close cooperation with the technology policy department of the BMWVK: they supported the organisation of the meetings (two or three times a year) and published a special newsletter for each meeting. The Council acted as an interface with technology policy but could not award research contracts (Peissl 1997). ${ }^{88}$ The aim of coordination in the Council was, among other things, to identify gaps in the information flow between ministries and interest groups and to present the results of TA studies in an appropriate forum (Rakos 1988, 206). Thus, even at this early stage, TA appeared as an informant and contributor to agenda-setting in the political context (I07). The Council was active until 1997 (I05).

During the amendment of the Research Promotion Act in 2000, the Council for Research and Technology Development was established at the Federal Ministry of Transport, Innovation and Technology (BMVIT) and replaced previous advisory bodies. ${ }^{89}$ Its task to provide strategic advice to the Federal Government and, where appropriate, also to Länder governments was ar-

85 The constituent meeting of the advisory council took place on 22.10.1985 (Archive of the OeAW: Technology Assessment/ISET. Summary protocol of the constituent meeting of the Advisory Council for Technology Assessment of 22.10.1985).

86 The Council of Ministers' speech on the establishment of this Council reads literally: 4. the targeted application of Science for Public Policy" is intended to achieve an improved relationship between the public, politics and science. This interaction will [...] be of central importance and should therefore be coordinated by an advisory council, which could also be the link between the above-mentioned institute [ISET, author's note] and the public. [...] This Advisory Council for Technology Assessment" should identify technology-related trends and developments and their consequences in good time for both political decisions and the general public" (translation by authors). (Archive of the OeAW: Technology Assessment/ISET. Report and application to the Council of Ministers Technology Assessment/Technology Assessment". Proposal for the establishment of an Advisory Council for Technology Assessment" (2.7.1985), p. 4. Supplement to the letter from Norbert Rozsenich, 29.7.1985).

The Council consisted of representatives of the administration (various ministries) chaired by the BMWF, of science (Austrian Academy of Sciences, Federal Conference of Scientific and Artistic Staff, Ludwig-Boltzmann-Gesellschaft, Austrian Rectors' Conference, Forschungsgesellschaft Graz, UBA, Federal Experimental and Research Institute Arsenal, Environmental Protection Fund) and of the social partners (Archive of the OeAW: Technology Assessment/ISET. Report and proposal to the Council of Ministers Technology Evaluation/Technology Assessment". Application for the establishment of an Advisory Council for Technology Assessment" (2.7.1985); enclosure of the letter from Norbert Rozsenich of 29.7.1985).

87 Archive of the OeAW: ISET. Letter from Norbert Rozsenich to Otto Hittmair dated 1.4.1988.

88 See also in TAB-Brief No. 10, tab-beim-bundestag.de/en/pdf/publikationen/tab-brief/TAB-Brief-010.pdf (13.4.2018), p. 26.

89 This Council is to replace the previous advisory bodies (Austrian Council for Science and Research, Research Promotion Council, Council for Technology Development, etc.). The formulation of homogeneous strategic objectives, the elaboration of priority guidelines for the national RTD programmes and the ministries and funds entrusted with their implementation as well as the ongoing review of the corresponding implementation steps and, last but not least, the ongoing assistance in strengthening the Austrian position in international RTD cooperation are essential tasks of the new Council". (parliament.gv.at/PAKT/VHG/XXI/I/__00164/fnameorig_601755.html, 13 April 2018, translated by authors) 
gued on the grounds of an intensified global competitive situation and changes in the national and international environment. The Ministry intended the Council's work to coordinate all relevant political, strategic, and operational measures at the federal level.90

Table 2: Austrian advisory bodies on technology policy

\begin{tabular}{|c|c|c|c|}
\hline Period & Name & Members & Comments \\
\hline 1985-1987 & $\begin{array}{l}\text { Advisory Council for Technology } \\
\text { Assessment }\end{array}$ & $\begin{array}{l}\text { BMWF (chair), ministries, Austrian Academy of } \\
\text { Sciences, Buko, LBG, Rectors' Conference, social } \\
\text { partners etc. plus the chairman of the ISET or TAU } \\
\text { advisory board as well as director and deputy director }\end{array}$ & \\
\hline 1988-1997 & Council for Technology Development & $\begin{array}{l}\text { BMWVK (Chair), similar composition to the Advisory } \\
\text { Board, plus members }\end{array}$ & $\begin{array}{l}\text { secretariat: TAU, } \\
\text { then ITA }\end{array}$ \\
\hline $\begin{array}{r}\text { from } \\
2000\end{array}$ & $\begin{array}{l}\text { Council for Research and Technology } \\
\text { Development }\end{array}$ & $\begin{array}{l}\text { Eight voting ad-personam members plus the } \\
\text { Ministers of Finance, Innovation/Technology and } \\
\text { Science/Research }\end{array}$ & $\begin{array}{l}\text { with an office; from } 2004 \\
\text { with its legal persona }\end{array}$ \\
\hline
\end{tabular}

At the beginning of 1999, the ITA team moved again because other Academy units needed the previous ITA rooms in Postgasse in the $1^{\text {st }}$ district. The OeAW adapted a large flat in an old building in the $3^{\text {rd }}$ district near the centre, in which the Institute remained until 2017 (see Table 4). The team continued its research work with increasing intensity. During this period, for example, the following activities took place: several projects in the field of Health Technology Assessment; the ITA's work on attitudes to technology in general and genetic engineering in particular in the context of the Eurobarometer projects; a study on the green bio-refinery; the start of a series of studies on electronic administration; and the first habilitation project at the ITA on cyberscience took place (more on this in section 3.1).

In June 2003, all social scientific institutes of the OeAW were subjected to an external evaluation (see also Table 1). Within the evaluation committee, Ortwin Renn, professor at the University of Stuttgart and head of the then TA-Akademie Baden-Württemberg, was responsible for TA. This evaluation turned out very beneficial for ITA: the evaluators praised the scientific achievements, the only area in need of a more explicit orientation was environmental technologies. Also, they proposed strong external (thematic and target group-oriented) feedback - a recommendation ${ }^{11}$ that could be taken into account in the following years (see 3.1). Besides, the evaluation report recommended a corresponding structural change within the ITA: it suggested the spin-off of the area of Health Technology Assessment (HTA), which the international community understood as a discipline independent of TA. The Academy did not take up this suggestion for the time being - three years were to pass before not the OeAW but the Ludwig-Boltzmann Gesellschaft founded the HTA Institute. Furthermore, the partial reorganisation of the OeAW research portfolio resulting from the entire evaluation led to the refocusing of the Research Centre for Institutional Change and Integration (IWE) towards European research ${ }^{92}$. Eventually, the last remaining IWE employee in the field of media research (which had emerged from the former ISOZÖK), Michael Latzer, became part of the ITA team (see Figure 1).

Concluding this phase, we interpret the programme of the symposium "TA and Policy. Two Decades of Technology Assessment and Politics - Looking Back to the Future" of May 30, 2005, as a sign of the consolidation of the inter- and transdisciplinary approach of ITA. Linking of multi-perspective scientific analysis with policy and society advice was now at the core of ITA's work: in addition to experiences from the (international and German-speaking) TA community, the dialogue with TA addressees and clients in Austria was explicitly emphasised (Tichy 2005).

90 Parliamentary correspondence No 319 of 26.5.2000; online: parlament.gv.at/PAKT/PR/JAHR_2000/PK0319/ (13.4.2018).

91 Archive of the ITA: report on the evaluation of the social science research institutions of the Austrian Academy of Sciences. January 2004. professors on the evaluation committee: Karl Ulrich Mayer (chair), Jürgen Friedrichs, Jürgen von Hagen, Ron Lesthaeghe, Ortwin Renn (focus on TA).

92 Its three areas of work (migration, media research and EU research) have each been institutionalised in different ways. While the Migration Research Unit was transferred to the newly founded Commission for Migration Research (Director: Heinz Faßmann) after the evaluation, the EU Research Unit (Director: Sonja Puntscher-Riekmann) developed into the Institute for European Integration Research (EIF), which remained at the Austrian Academy of Sciences for a few years and which, under the new director (Gerda Falkner), was founded on January 1, 2007 in the course of the Academy's financial crisis it has been transferred in April 2012 to the University of Vienna (intern.newsletter.univie.ac.at/interner-newsletternew/april-2012/?no_cache=1\#a40600, 13.4.2018). 


\subsection{EXPANDING AND BROADENING TOPICS, GENERATIONAL CHANGE AND CRISIS (2006-2011)}

When Gunther Tichy retired from his position as director ${ }^{93}$ at the end of $2005^{94}$ (Nentwich/Peissl 2005), TA was well established as a research field both nationally and internationally. Accordingly, an international job advertisement in 2005 determined his successor. ${ }^{95}$

When Michael Nentwich became the new director on January 1, 2006, TA at the Austrian Academy of Sciences was in the hands of a TA practitioner and habilitated science and technology researcher who had experienced the laborious and lengthy establishment of this field himself from the very beginning. Nentwich, who was part of the ITA team, established a cooperative management style (inspired by the original technology assessment working group). This style resulted not least from the specific nature of TA projects, especially the interdisciplinary cooperation - and thus the recognition of various expertise as basically equal. Simultaneously, the team gradually made strategic expansions and changes to the Institute's focus (e.g., focusing on energy issues or activities in participatory procedures, see Section 3.1). These changes were implemented against the background of an independent and differentiated understanding of TA, emphasising a shared understanding and interdisciplinary work (I05).

In the first years under Nentwich's leadership, we record the most significant changes in staffing levels to date (under longterm professional preparation, I05). While in 2006 there were 15 people (of which 12 scientists), one year later, 20 (16 scientists) and in 2008, 26 (22 scientists) were working at the ITA on a short-term basis (see Figure 4). ${ }^{96}$ Third-party funds almost exclusively financed this increase. Despite changes of individual staff members, the total number has remained more or less stable to this day, apart from a few interim changes (see section 3.4), implying a renewed rejuvenation of the institute.

The spin-off of the HTA division, transferred to a newly established Ludwig Boltzmann Institute on March 1, 2006, contributed to this "generational change". The field of medical TA had already begun under Ernest Braun, and over the years, more and more developed towards an HTA group. ${ }^{97}$ In the 2004 evaluation report (see above), the foundation of an independent HTA institute (at the Austrian Academy of Sciences) or a massive expansion as an HTA department at the ITA was suggested. However, the OeAW took up neither option despite intensive efforts by the ITA. In the Ludwig-Boltzmann-Gesellschaft (LBG) reform in Austria, a call for institutes of "new types" was issued, intended to reduce the 135 institutes and research centres to about 50, including new foundations. ${ }^{98}$ This call represented a promising option for the institutionalisation of HTA in Austria. On the initiative of Claudia Wild, a long-standing ITA staff member, an application for a Ludwig Boltzmann Institute for Health Technology Assessment (LBI-HTA) was submitted, which was to be supported by the Academy as a partner ${ }^{99}$. Despite the OeAW initially declaring its interest in a "Letter of Intent"100 to support the project, it surprisingly withdrew from the co-financing of the institute in the end (I11). As a replacement for the withdrawal, Wild organised UMIT (Private University for Health Sciences, Medical Informatics and Technology in Hall in Tyrol) as an academic partner with the support of the LBG. Since the departure of the HTA group in April 2006, there has been no institutional relationship with the ITA - apart from informal contacts (I11).

93 Directors of OeAW research institutions may only hold their position until the end of the year in which they turn 67

94 To date, however, he continues to work as a consultant at the economic research institute WIFO and has published numerous economic publications, some of which are related to TA (z.B. TICHY 2016).

95 In addition to internal candidates from ITA (the long-standing Deputy Director Walter Peissl, a doctor of sociology and business administration, the habilitated media economist Michael Latzer and the lawyer and habilitated science and technology researcher Michael Nentwich), several other experts from Germany and abroad applied for the position.

96 This census does not refer to full-time equivalents, but to heads; source: internal calculation.

97 A general characteristic of HTA is a high level of application, i.e. the will to actively intervene in policy advice with effects to become visible in political action in the relatively short term (e.g. in legislation or in the funding decisions of the health insurance funds). While in early projects (such as the PACS project from 1996/97) soft" social science methods were still being applied, these were increasingly developed further in the direction of evidence-based medicine" (EBM) - also due to the need for legal validity of the results, which is regarded as essential for some HTA projects. At the current time (2017), there are other institutions in Austria in the field of HTA besides the Ludwig Boltzmann Institute for HTA, which, however, have different focal points (I11).

98 From 2002, the Ludwig-Boltzmann-Gesellschaft was fundamentally and comprehensively modernised. Since 2004/05, the LBG has been able to carry out three successful tenders for the establishment of new institutes and founded twelve new institutes (see $\mathrm{lbg}$.ac.at/themen/die-lbg-1960, 13.4.2018).

99 The rules of the LBG stipulate as a condition that each new institute must be co-financed at least one scientific partner institution in addition to practice partners.

100 The authors only have a draft version of this, but its existence has been confirmed in several interviews (I05, I11). 
The spin-off of HTA from ITA may also indicate a differentiation and delimitation of a TA-specific profile. The profile was also strengthened internally within ITA from 2007 with some new additions. The area of "technology and sustainability" was redefined and expanded to include new fields such as the energy sector (see section 3.1). Furthermore, the mid-term research programme was developed accordingly in several closed meetings starting in 2006.

An essential step towards profiling and internationalisation was taken based on the new OeAW rules of procedure (2007), which required scientific advisory boards for all institutes instead of the previously usual boards composed internally of members of the Scholarly Society (see Table 3). In his founding proposals, Ernest Braun had already referred to the necessity to install a scientific advisory board for quality assurance of the institutes' work. In December 2007/08, the Academy implemented this by convening a scientific advisory board (SAB) made of members of the international TA community and TArelated scientific institutions. ${ }^{101}$ The advisory board contributes to discussing distinctive TA aspects of the ITA's work, such as trans- and interdisciplinarity or the tension between scientific work and policy advice, and externally reflecting on the further development of the research field of TA in Austria. With the SAB meetings, which initially took place every two years, later annually ${ }^{102}$, English was also strengthened as the reporting language at the ITA. While many publications, especially from international projects, had already been published in English by then, from 2008, there was an additional necessity to write the annual reports and the medium-term research programme in English to benefit the English-speaking SAB members.

Table 3: Advisory bodies for TA in Austria

\begin{tabular}{c|l|l}
\hline \multicolumn{1}{c|}{ Period } & \multicolumn{1}{|c|}{ Name } & \multicolumn{1}{c}{ Chair } \\
\hline 1984-1985 & TA project group in the BMWF & N. Rozsenich \\
\hline 1985-1987 & Advisory board of ISET (the Austrian Academy of Sciences) & G. Bruckmann \\
\hline 1988-1993 & Advisory board of TAU (the Austrian Academy of Sciences) & F. Paschke \\
\hline 1994-2007 & Advisory board of the ITA (the Austrian Academy of Sciences) & F. Paschke, from 1999 W. Schneider \\
\hline from 2008 & $\begin{array}{l}\text { Scientific Advisory Board (SAB) of ITA } \\
\text { (the Austrian Academy of Sciences) }\end{array}$ & $\begin{array}{l}\text { A. Grunwald, from 2014 A. Bora, } \\
\text { from 2018 M. Bourrier }\end{array}$ \\
\hline
\end{tabular}

We can illustrate the difficulties that interdisciplinary research fields face when established in the framework of disciplinary, hierarchically oriented institutions in the long term (cf. Section 4) by a severe caesura in the ITA history. While TA had consolidated and become scientifically grounded, the Institute struggled with external developments: the crisis of the Academy's budget ${ }^{103}$ posed a fundamental threat to the existence of the ITA for years. Cuts in the budget of the OeAW (with corresponding adjustments to the institute's budget ${ }^{104}$ ) led to considerations within the Academy to close research institutions in the short and medium-term or transfer them over to universities. ${ }^{105}$ At that time, the OeAW focused on basic research and relied on "excellence", which publication standards could measure. In contrast, the ITA, with its mission for political and social advice, such as contributing to social debates, also relies on other standards - inflicting a conflict over different interpretations of

101 The composition of the SAB changes every three to six years. The first six Advisory Board members in 2008-2013 were Alfons Bora (Bielefeld), Linda Garcia (Washington), Armin Grunwald (Karlsruhe/Berlin), Ann Macintosh (Leeds), Thomas Saretzki (Lüneburg) and Joyce Tait (Edinburgh) Following the departure of Tait and Macintosh, Regine Kollek (Hamburg) and Mathilde Bourrier (Geneva) joined in 2014. From 2018 on, the ITA-SAB will only have five members: the afore mentioned R. Kollek and M. Bourrier, and new members Michael Decker (Karlsruhe), Sergio Bellucci (Zurich) and Sabine Maasen (Munich).

102 The meeting dates were: 5-6 November 2008, 5 November 2010, 13 December 2012, 27 November 2014, 11 December 2015 , (2 June 2015), 15 December 2016, 12 March 2018.

103 The global financial crisis of 2008 led to a general reduction in government spending on research and development, which also led the Academy into a budget crisis from mid-2008 at the latest, and had an impact on everyday work. For example, the twelfth rule" (instead of a new annual budget, only one twelfth of last year's annual budget was released each month), a stop on overtime and a requirement for approval of material expenses above EUR 1,000 applied; furthermore, all deposits from previous years were confiscated. Archive of the ITA: internal documents.

104 Thus, the basic budget of the ITA 2008 was reduced by about one tenth compared to the previous year, which was temporarily compensated by income from third-party funded projects. Archive of the ITA: Internal documents.

105 This was finally put into practice several times in 2012; among others, the Institute for European Integration Research (EIF), which is a "cousin" of the ITA, as it were (see Figure 1), was assigned to the University of Vienna. 
"scientificity". The ITA's subsequent broad-based communication offensive ${ }^{106}$ intended to secure the Institute's support both within the Academy and external actors. The broadening of the ITA's portfolio led to the individualisation of contacts with specialist departments of various ministries. As a result, the traditionally excellent connections to the Ministry of Science and Research ebbed away (I05).

Nevertheless, the message was heard, especially in the Ministry of Science, by section head Barbara Weitgruber and the department responsible for negotiations on the OeAW budget and performance agreement. At the end of 2010, considerations on the first draft of the Austrian Academy of Sciences' strategic development plan - a basis for the performance agreement to be concluded for the first time with the BMWF - still envisaged outsourcing the ITA from the Academy together with many other research institutions. Finally, the ITA remained in the almost final draft of February $2011^{107}$ as an "interdepartmental" institute outside other content clusters (and therefore assigned to the Academy as a whole). The performance agreement 201214, finally concluded in autumn 2011, not only contained a mandate for the OeAW as a whole, especially for the Learned Society, to become more involved in the field of political and social advice. It also specifically stated that the ITA should reorient itself "with a view to political and societal advice" (own translation) ${ }^{108}$. For the ITA, this official recognition of the dual focus on research and political and societal consulting confirmed its previous self-image. Internally, this development focused on strategic aspects of the ITA's institutional embedding - from the necessary strengthening of public relations to targeted communication with political actors and the relevant administration.

However, the difficulties of working across disciplines in a disciplinary context were also sometimes expressed at the individual level, such as the particularly long and challenging processes of tenure assessment for staff members have shown. Despite the undisputed professional reputation of the candidate and the support of the director ${ }^{109}$, the OeAW evaluation commission was unable to agree on a positive recommendation to the presiding committee in 2006 due to disciplinary differences of opinion. Given the negative recommendation of the commission, the presiding committee did not make a decision. Interventions by the former head of the institute, Tichy, and the former chairman of the board of trustees, Paschke, did not change the unsatisfactory situation, nor did a letter from the current ITA director to the executive board and one from the scientific advisory board. Finally, the OeAW found a partly Academy-external interim solution until the second (successful) evaluation of the candidate.

The third international evaluation took place in 2011, marking the end of a turbulent phase. The three-member committee chaired by Dominique Foray (see Table 1) certified the ITA as excellent, both in terms of academic performance and policy advice, both in the Austrian and the European context. Recommendations focused on strengthening links with universities and teaching while emphasising the need to maintain political independence (as guaranteed by the OeAW). ${ }^{110}$

106 Already in October 2008, an information brochure on the work of the ITA was published, for which the then OeAW president Peter Schuster could be won over as the author of a foreword and some domestic and foreign testimonials. In September, a dossier with Ten good reasons to keep and expand the ITA at the Austrian Academy of Sciences" (translation by authors) was distributed; in October 2009, the new OeAW president Helmut Denk was invited to an information event; the strategy paper ITA 2020" was also written this month, in which the necessity and usefulness of expanding institutionalised technology assessment in Austria and at the Academy was outlined. In addition to the undeniable scientific excellence of the ITA team (which was finally re-established in the institute evaluation in 2011), the paper also referred to the central goal of TA to contribute to the public discourse on technologies and their consequences as well as to the political shaping of the handling of technologies. Based on these documents, the ITA director conducted numerous discussions with actors inside and outside the Academy, especially with actors in the Ministry of Science, with the aim of strengthening the understanding of the social and political relevance of TA.

107 OeAW Development Plan 2012-2014 (draft), table presentation for the special session of the general meeting on 15 February 2011 , Annex to item 3, p. 54/Fn. 35.

108 Performance Agreement 2012-2014 between the Federal Ministry of Science and Research and the Austrian Academy of Sciences, concluded on 4.11.2011, oeaw.ac.at/fileadmin/NEWS/2011/pdf/Leistungsvereinbarung_2012-14.pdf(13.4.2018), p. 9.

109 At the time of the evaluation, the candidate was working on his habilitation, has since habilitated and has had several appointments at national and international universities.

110 Archive of the ITA: Evaluation Report, Draft 2012. 


\subsection{CONTINUITY AND PARLIAMENTARY TA: THE LATEST DEVELOPMENT (2012-2017)}

Despite difficulties and setbacks, the ITA was thus able to maintain its position as part of the OeAW. Increasingly, the Academy headquarters see the ITA as an essential element of the Academy's strategy in political and societal advice, which is also anchored in its performance agreement with the Ministry since 2012 (see above). Temporarily the institute was even assigned to the "Scholarly Society" pillar (and not to the "Research" pillar) after the change in the business division of the central administration by the presiding committee Anton Zeilinger/Michael Alram in 2013 because they located the "Policy and Society Advice" division of the OeAW there. However, due to the day-to-day practical requirements of a research institute with numerous externally funded projects, this is outdated.

On the one hand, we characterise the latest phase of the development of the ITA by a slight growth based on third-party funding. This growth is partly due to a further expansion of EU project work in the research framework programmes FP6, FP7 and H2020 of the European Union - with the ITA sometimes coordinating the projects. Also, trainees' numbers (to around ten per year) increased, and the OeAW decided to regulate their status by regular contracts.

On the other hand, we find this phase characterised by the continuity of long-established project lines in political advice. In this context, we see the expansion of contacts with the Chamber of Labour and the corresponding studies about data protection. The repeated extension of the NanoTrust project, initially for the Federal Ministry of Transport, Innovation and Technology (BMVIT), and from 2013 also for the Ministries of Health ${ }^{111}$, Social Affairs ${ }^{112}$ and the Environment ${ }^{113}$, is also worthy of note. This project deals with monitoring nanomaterials and risk governance in Austria (see section 3.1).

Finally, a resurgence of relations with Parliament, which have been rather uninspired for many years (see above, particularly 1991-1994, section 2.5), marks this latest phase. From 2012 onwards, the ITA director made increased efforts to bring the Austrian Parliament's advice on technology issues closer to international standards. Together with its strategic partner the Austrian Institute of Technology (AIT) ${ }^{114}$, it finally succeeded in carrying out a multi-stage feasibility study on behalf of the Parliamentary Directorate in 2014-2016, which resulted in an international tender. In this tender, the ITA and the AIT jointly prevailed and concluded a framework contract for long-term cooperation in mid-2017. In 2016, the ITA held the presidency of the EPTA network for the first time. It organised several high-ranking events in Austria for the network, including a conference with Austrian and foreign parliamentarians on the topic of "The future of digital work" in the parliament building (for details, see section 3.2).

Another remarkable aspect of the last few years is the professionalisation and specialisation of the office team: while in previous years all functions, such as project management, event management or public relations, were performed jointly and ad hoc by all (scientific and non-scientific) staff members, since 2014 there has been a separate office for public relations, initially financed by third-party funds, and in 2015 the project management team was supplemented with a trained project manager after initial good experiences in the coordination of an EU project (SurPRISE) (see section 3.4). It is precisely public relations work in the broader sense that is even more important for ITA than basic research institutes because of its advisory mandate. The more professional and specific the communication towards politics, administration and society, the more successful it is (on outreach and dissemination see section 3.5). The development in recent years shows this, not least regarding the institutional perception in parliament. At the ITA, at any given time, at least ten partially externally funded projects are running, three to five are being negotiated after awarding the contract, a between three and seven are in the application stage. Due to this large share (above 30\%) of third-party funding resulting from the addressee orientation of TA, the professional, detailed support of the scientific project leaders is essential to focus their capacities for actual project work and publication activities. Both newly established offices work closely together and complement each other with the corresponding central offices of the OeAW.

111 Federal Ministry of Health (BMG), integrated into the BMASK in 2018.

112 Federal Ministry of Labour, Social Affairs and Consumer Protection (BMASK), since 2018 Federal Ministry of Labour, Social Affairs, Health and Consumer Protection.

113 Federal Ministry of Agriculture, Forestry, Environment and Water Management (BMLFUW), since 2018 Federal Ministry for Sustainability and Tourism (BMNT).

114 At the AIT, the cooperation partner of the ITA is the "Innovation Systems Department", which has been called "Center for Innovation Systems \& Policy" since 2017. 
The personnel growth since 2007, more in terms of heads than full-time equivalents, has led to an increasing shortage of space at the Strohgasse location. After the failure of various options, a complete relocation to the current Apostelgasse location, a modern office building, took place in summer 2017 (see Table 4).

Table 4: Change of location of TA in Vienna

\begin{tabular}{|c|c|c|}
\hline Period & Address & Note \\
\hline $1985-1990$ & 1, Fleischmarkt 20 & Old building flat, shared with ISET, later ISEF \\
\hline $1989 / 90$ & 2, Czerningasse 9 & Temporary additional flat in an old building \\
\hline 1990-1998 & 1 , Postgasse $7 / 4$ & Institute building of the OeAW \\
\hline 1999-2017 & 3, Strohgasse $45,3^{\text {rd }}$ floor & Flat in an old building \\
\hline as of 2007 & 3. Strohgasse $45,4^{\text {th }}$ floor & Two additional rooms \\
\hline from 2016 & 3, Strohgasse $45,2^{\text {nd }}$ floor & Nine additional rooms \\
\hline from 2017 & 3, Apostelgasse $23,2^{\text {nd }} \& 3^{\text {rd }}$ floors & Institute building of the OeAW \\
\hline
\end{tabular}




\section{LONGITUDINAL DEVELOPMENTS OF TA AT THE AUSTRIAN ACADEMY OF SCIENCES}

\subsection{THE ITA PORTFOLIO: THEMATIC DYNAMICS AND CONSISTENCY}

The ITA's and its predecessors' organised their scientific work and consulting activities in project form from the very beginning. The ITA primarily directed its work at external addressees, who usually also acted as financiers (sponsors, clients). Over time, topics, methods, and central areas of work and the addressees and sponsors changed and developed further. ${ }^{115}$

\section{ON THEMATIC DEVELOPMENT}

The ISET Technology Assessment Working Group between 1985 and 1987 focused on "Information and Communication Technologies" (ICT). It carried out two studies in this field: a study on "Computer procurement as a tool of government technology policy" and a comprehensive "Technology Assessment of new telecommunications services". Another topic was in the environmental field ("Air pollution from road vehicles") and a more general one in the field of technology policy ("Survival through technical innovation").

After the split into ISEF and TAU, the TAU carried out its first study for the Verbundgesellschaft; it compared the concept of technology assessment with environmental impact assessment (Braun et al. 1988; Rakos 1988).

The TAU directly continued the ICT focus of ISET from 1988 onwards and dealt with developments such as local telecommunications networks (LAN), employment effects of telecommunications innovations, teleports and the legal consequences of new telecommunications technologies.

115 To trace and analyse this development of the portfolio in detail, both the minutes of the so-called Kuratorium and SAB meetings as well as the annual reports from 1989 onwards and the medium-term research programmes drawn up from 2005 onwards are available as sources. Furthermore, the ITA has created a complete database of all projects ever carried out at TAU and ITA since 1996, based on the annual reports. This database has been accessible and searchable on the public ITA website since then and is continuously updated. With the introduction of the OeAW-wide AkademIS database, the metadata of all projects (as well as publications) were retroactively entered into the new system and from then on continuously updated. Within the framework of the internal ITA research project Pol[ITA] (2016-2018), an adjusted Excel database of all those ITA projects with research and consulting character in the narrower sense was created based on these complete AkademIS data. As of June 2017, this Excel database contains 193 ITA projects, the oldest of which dates from 1987/1988. For evaluation purposes, the data available in AkademIS was supplemented by the Pol[ITA] project team with a number of additional parameters per project, in order to open up above all the content and methodological dimensions: all projects were assigned to one or more of seven technology groups (biotechnology, energy technologies etc.), one study type (comprehensive TA, partial TA, overview study or capacity building), one or more of three ideal-typical methodological approaches (expert TA, stakeholder or lay participation) and one or more of sixteen typical TA topics (privacy, work, environmental risks etc.). These TA topics were identified as adequate descriptions of the projects by a bottom-up analysis and an iterative assignment process by the Pol[ITA] group. Furthermore, the donors were classified, the budget and the number of ITA staff involved and, finally, the project duration was determined. The Pol[ITA] database thus provides a detailed picture of project activities over time. While in the Pol[ITA] project it was evaluated primarily from the perspective of pattern finding in connection with the policy advice activities of the ITA (see KASTENHOFER et al. 2018), it is used here to describe the historical development of the institute's research portfolio. 
From the initial preoccupation with information technologies in the medical field, such as the Medcard (1991) or digital radiology (1996), a focus on health technology assessment and evidence-based medicine developed from 1997 onwards, with many pilot studies, for example on shock wave therapy (1998), intensive care bed planning (2002) or hepatitis C (2004). This area was finally outsourced to a separate institute of the Ludwig Boltzmann Society in 2006 (see Section 2.7).

As early as spring 1990, the ITA expanded its portfolio beyond the broad topic of ICT: through an internal project on "TA of genetically engineered drugs" and, in cooperation with the Federal Environment Agency, in three projects on the regulation of plant genetic engineering; as well as through a large cooperative project on renewable raw materials. The four areas of ICT, biotechnology, medicine, and environment remained a focus of research at ITA until 2006, but were differentiated later-on and developed continuously in the ways described below.

From 2007 onwards, the focus on environmental technologies or environmental aspects of new technologies, such as oil filters (1991), aerogels (1994), green bio-refinery (2001-03) and others, became part of a priority area of sustainability and technology. Within this area, energy issues became increasingly important, starting in 2007/08 with the participatory assessment of new energy technologies in everyday life, in several projects on smart meters (2010-11) or generally on the transition towards a non-fossil-based energy infrastructure. From 2006 onwards, individual ITA staff members also dealt with sensitizing technical professions for sustainability issues. This development reached a preliminary peak in 2017/18 with a course for university lecturers and one for students at the TU Vienna, focusing on TA methods and approaches. From 2008 onwards, the ITA took up again "technology and ageing", which had already been in ITA's portfolio between 1991 and 1996. It focused on it in light of a comprehensive sustainability perspective.

The initial focus on the risks and regulation of genetic engineering increasingly broadened and integrated public perception issues of this controversial technology (e.g., contributing to Eurobarometer surveys, 1996-2004). From 2004 onwards, the topic focused on the broader perspective of bioethical issues and the study of technology controversies. The combination of public perception issues, risk and regulation, led to developing a governance focus on emerging technologies (such as nanotechnologies) since 2006. From 2007 onwards, many projects on the management of nanomaterials and nanoparticles were carried out, both at national and European levels. Other more recent topics from this governance perspective include synthetic and systems biology (from 2009) and neuro-enhancement (2013-16)

The Information and Communication Technologies (ICT) priority has diversified over the years and was reconceptualized and renamed as "Information Society" in 2005. In particular, from 1998 onwards, the Institute dealt with information and communication technologies in science (cyberscience) in several studies, from a theoretical and practical perspective (e.g. on digital copyright 2004-06). Also, the ITA carried out many projects on electronic administration and participation in Austria, at the EU level or between several European countries on a comparative basis since 1999. After 1999, the issue of privacy predominantly showed on the agenda. It resulted in numerous projects, among others, in a series of small studies for the Austrian Chamber of Labour (e.g. on mobile geo-data 2012, credit scoring 2014 or vehicles of the future 2016). Besides, the ITA participated (and partly coordinated) several EU projects on the area of conflict between security technologies and privacy between 2006 and 2015 (e.g. on guidelines for privacy-preserving security technologies 2006-08 or on the acceptance and design of security technologies in conformity with fundamental rights 2012-15).

Since 2015 at the latest, the Institute's portfolio has expanded towards robotics, starting with a study for the Austrian Parliament on Industry 4.0 and one for the European Parliament on 3D printing processes (from 2016), as well as overview studies on robotics in Austria (2017) and autonomous delivery drones (2018). As can be expected, robotics will remain a core subject of ITA due to the emergence of the multifaceted field of artificial intelligence, amongst other factors.

In addition to the technology fields and problem areas outlined above, the ITA has dealt with participatory procedures in technology assessment in various ways since 1993: conceptually (Aichholzer/Torgersen 1994; Kolm et al. 1995), observatory (e.g. at the Genetic Engineering Consensus Conference in Great Britain in 1993), analytical (in the projects EUROpTA 19972000 and TechPol 2005/06), advisory (e.g. at the first Austrian (Youth) Consensus Conference on Ozone Pollution 1996 or the first Citizens' Conference on genetic data 2003 within the framework of the initiative "Innovative Austria") and practical since 1996. Stakeholder participation was already at the core of the ITA lighthouse project Technologie-Delphi-Austria (19961998): in this project, several thousand Austrian experts were interviewed (in writing) in two rounds; additionally, in the runup to the project, about 15-20 stakeholders and experts met several times in eight thematic groups to elaborate on the contents of the Delphi survey. Since a first citizen participation activity to assess energy technologies in 2007/08, the ITA has carried out several participatory processes (e.g. in the worldwide WWViews project on climate policy in 2008-10 or as coordinator of the SurPRISE project on security and monitoring with more than 2000 participants in eleven European states, 
among others). It thereby significantly contributed to the development of new methods, such as the CIVISTI method. CIVISTI was first applied in an EU project in 2008 and later several times at regional, national and international level. From 2015 onwards, the CIMULACT project used an updated version of this method to develop citizen visions for future EU research policy throughout Europe.

More recently, the PACITA project (funded by the EU 2011-15), in which ITA was significantly involved in several work packages, is worth mentioning because of its thematic breadth and the determined goal to spread TA or parliamentary TA in Europe. Furthermore, the ITA was involved in the EU project PROSO, which ran between 2016 and 2018 and aimed at promoting public participation in responsible research and innovation (RRI), as well as the projects NERRI (2013-16) and Synenergene (2013-17).

Investigating the allocations to the seven technology areas covered by the TAU and the ITA in detail, the Pol[ITA] project draws the following picture: with 78 projects, by far the most significant number of projects are located in the ICT area, followed by biotechnology in the broader sense with 30 projects; the institute dealt with medicine in a total of 24 , the environmental area in 21, energy issues in 17 and advanced materials (especially nanomaterials) in 13 projects; the area of robotics is already present with six new projects. ${ }^{116}$

\section{TA APPROACHES}

Finally, the Pol[ITA] project database's retrospective evaluation yields exciting results regarding the primarily applied TA approaches. Almost all projects (185) use at least an expert-oriented approach (at least to some extent), three quarters (148) exclusively. Stakeholder participation was crucial in 30 projects, at first for the Austrian Parliament in 1991 and then on a large scale in 1996-98 for the Technology Delphi. The ITA organised lay participation in 23 cases, i.e. in $8 \%$ of all ITA projects, all of which were only implemented from 2006 onwards, i.e. in the last twelve years.

\section{STUDY TYPES}

The Pol[ITA] project categorised less than a tenth of all projects (15 out of 193) as "comprehensive TA", which means that a single project deals with all potential TA aspects and dimensions. Of these, with a few exceptions, all projects took place in the early phase of the institute; more recently, only two are in this category: the Cyberscience project (1998-2003) and the NanoTrust project have been running for over ten years. In the relative majority of the projects (75), "partial" TAs were carried out, i.e., due to the available time and financial resources or the specific interest of the client, these studies only addressed individual TA-relevant aspects, such as environmental risks or the impact on privacy. In a quarter of all projects (48), the Institute provided a broad topic overview and presented the TA aspects to investigate potentially without going into depth within this study. Just over a further quarter (55) were assigned to the category "capacity building": these projects mainly aimed at building methodological or institutional knowledge, creating particular databases, providing advice in the preparation of research programmes, or for other reasons did not primarily aim at assessing technologies in the narrower sense, but rather aimed at general, reflexive purposes. ${ }^{117}$

\section{CONTRACTING AUTHORITIES}

The clients or financiers of TA projects at the Austrian Academy of Sciences are very diverse. They are almost exclusively publicly funded bodies, whether at the national or international level, and various funds. In total, the TAU and the ITA have jointly raised around EUR 12.5 million ${ }^{118}$ over the thirty years. The ITA financed 27 of the 193 projects from its own resources. The following details how the circle of financiers has developed in the first 30 years.

116 Multiple allocation was possible; in addition, there are 31 projects where allocation to technologies is not meaningful.

117 The average project duration has increased slightly over time: the average project duration rose from 20 to 24 months in the three decades $1987-$ 1996, 1997-2006 and 2007-2016, with a slight decrease to 19 in the middle decade, when a total of 84 projects were launched, compared to 36 in the first and 73 in the third. Less than a tenth of all projects (26) were short projects with a duration of less than half a year, of which slightly less than half were from the last ten years. About a third (64) lasted between half a year and a year, and just under a third between one and two years (53) or more than two years (57), with a maximum of ten years so far in the NanoTrust project and even 16 years for the Strategic Environmental Assessment (which, however, was much less intensive than the other projects). Two thirds of the 23 projects with the longest durations (more than three years) date from after 2000.

118 Nominally, not converted to purchasing power at the time. 
In the first years, the TAU was mainly active for Austrian clients, including several federal ministries (initially science, consumer protection, environment and health), Verbundgesellschaft and the postal telegraph administration. The first EU or EC project, which was to be followed by many others (36 in total by 2017), started in 1988 on broadband communication - i.e. long before Austria became an EU member. From 1992 onwards, the Austrian National Bank occasionally financed projects, as well as the Federal Environment Agency in 1993, the Consumer Centre Hamburg in 1995, the FWF from 1996, also the Ministry of Economics from 1998 and, as a frequent client until today, the Ministry of Technology and Innovation or the FFG in various programmes (GEN-AU, Climate and Energy Funds and others), as well as the Federal Chancellery on several occasions. Since 2002, the Chamber of Labour has financed eight smaller projects, and the Council for Research and Technology Development financed two projects between 2003 and 2006. The early HTA projects were funded, for example, by the Main Association of Austrian Social Insurance Institutions and the UMIT University in Tyrol. The Volkswagen Foundation financed one project in 2008, the European Science Foundation (ESF) one from 2009, and the Norwegian Science Council. From 2017, the ITA added the Cultural Department of the City of Vienna as a funder of its research portfolio. There were two projects for the Austrian Parliament at the beginning of the TAU period between 1989 and 1992 and then only three again from 2015 and several from 2017, one for the European Parliament in the 1990s, and seven (so far) based on the Committee for Scientific and Technology Options Assessment (STOA) framework agreement since 2010.

\section{INTERDISCIPLINARITY AND COOPERATION}

TA projects are naturally interdisciplinary and, therefore, usually not carried out by one person alone. Of the 193 projects between 1987 and 2017, just over a third (79) had more than one internal staff member (twelve in the case of TechnologyDelphi-Austria 1996-98, when the whole team was involved). The Pol[ITA] database assigned the other 114 projects to one of three case categories: (1) academic theses (dissertations, habilitations) are often monodisciplinary. (2) partial TA studies focus on a specific aspect of the object of investigation, whereby the ITA strengthens the interdisciplinary view by the involvement of an internal project advisory board and regular discussions of the entire ITA team. (3) Furthermore, the team ensures interdisciplinary cooperation in TA projects also through cooperation with external partners. In such cases, sometimes, only one member of staff at a TA institute is involved in the project.

The chronological sequence is also interesting: if one arranges the projects in chronological order and divides them into roughly two halves (96 projects had started before the beginning of 2004, and 97 projects after that), one sees that a large majority of the projects with only one internal staff member were carried out in the first half by the end of 2003 (88). Only about a third of all one-person projects (26) took place in the second half of the observation period. Conversely, the vast majority of the projects that are also internally collaborative are in the second half from 2004 onwards, namely 71 out of 79 . From this, we conclude that the Institute has also collaborated considerably more internally over the last ten years - partly due to the growth of the Institute - and not only with external cooperation partners. ${ }^{119}$ This development has significantly strengthened the interdisciplinary discourse at the Institute since regular changes of project teams are standard practice. It is not always the same partners and small groups who work on joint projects together, but rather, the teams regularly reassemble.

119 The number of external cooperation partners did not decrease during the same period, but continued to increase, since the entire research landscape - mainly due to the influence of the EU Research Framework Programmes, but also in Austria - clearly tends towards more cooperation. In many EU projects, there are now several dozen partners across Europe. 


\subsection{TA AND THE AUSTRIAN PARLIAMENT: AN ON-OFF RELATIONSHIP}

While TA had emerged internationally as an independent advisory body for parliaments (first at the US Congress), the founders institutionalized TA in Austria differently. Nevertheless, the TAU made an early attempt to offer TA for the parliament. Soon after its foundation, in spring 1990, the TAU prepared a statement on behalf of the Petitions Committee of the National Council on the construction of a $380 \mathrm{kV}$ power line from Kaprun to Zell am Ziller. ${ }^{120}$ Only two years later, the second opportunity arose to support the parliament. In 1991, after tough negotiations, the Austrian National Council for the first time (and incidentally uniquely so far) decided to activate the instrument of the Parliamentary Enquiry Commission ${ }^{121}$ on Genetic Engineering. The German Bundestag adopted this instrument already in 1988 on the German model. The aim was to lay the foundations for new law in a series of in-depth debates between parliament and experts over three months. ${ }^{122}$

Based on the German TA model123, Gunther Tichy proposed an Austrian model with recourse to the research unit as "technology assessment secretariat" ${ }^{\prime 24}$, a step that did not go smoothly. ${ }^{125}$ The differences between the TAU and the President of the National Council were mainly due to different views on how such commissions should work. Tichy interpreted the President's proposals as a unique form of sub-committee with expert hearings for consensual reporting. He argued that consensus prevented elaborating interdisciplinary aspects and could hardly be of use for specific questions. In turn, the model would require from members of parliament continuous cooperation and time. ${ }^{126}$ Therefore, Tichy's vision of the Enquiry Commission exceeded the procedure that had been customary up to that point and even considered an amendment of the Parliament's rules of procedure to be justified. It was a new instrument of the Parliament. Tichy considered "this procedure to be extremely important, in fact indispensable, for a comprehensive opinion-forming process of the members of the commission of enquiry and for strengthening the Parliament vis-a-vis the administration" (translated by authors). ${ }^{127}$

Finally, the Parliament entrusted the TAU by observing the parliamentary debate and presenting the various arguments. ${ }^{128}$ On its responsibility, it worked out an overall assessment of the subject of the negotiations in all its facets (Torgersen/Mikl 1992; Torgersen et al. 1992). Simultaneously, the Ministry of Health was already working on a law on genetic engineering; an advanced draft was published shortly before the Enquiry Commission's final report, subsequently leading to a disagreement between Parliament and the administration. The report of the members of parliament also recommends the establishment of a TA unit in parliament, apart from substantive comments on genetic engineering:

120 It was clarified to what extent the objections of the population - expressed by Petition 55 - were justified on scientific grounds and whether there were reasons from this perspective to refrain from this project. The statement considered energy policy aspects, technical alternatives, the effect of magnetic fields and other impacts on humans and the environment. The TAU concluded that under the given energy-policy framework conditions there was nothing to stand in the way of construction, but also suggested that fundamental questions of energy policy should be addressed.

121 The documents attached to the letter, such as correspondence and proposed approaches to the issue, show the slow pace of discussions with the Parliament. Tichy wrote a proposal for "Technology Assessment in Parliament" to the then President of the National Council Heinz Fischer and the respective science spokespersons of the parties. His proposal explicitly refers to the decision of the National Council of 1990: In their 'Working Agreement on the Formation of a Joint Federal Government for the Duration of the XVIII th Federal Assembly', coalition parties have agreed on a joint Federal Government for the duration of the XVIII ${ }^{\text {th }}$ Federal Assembly. Legislative Period of the National Council' of 17 December 1990, coalition parties laid down the 'inclusion of technology impacts in technology promotion'. In particular, reference is made [...] to [...] the establishment of a Commission of Inquiry for Research and Technology' in the area of the Parliament", as well as the "priority legal regulation for research and application of genetic engineering". (Introduction). (Archive of the OeAW: FTB. Letter from Gunther Tichy to President Werner Welzig of 17.1.1992; translated by authors).

122 Among the MPs who were particularly active at the time were Lothar Müller, Elisabeth Hlavac and Johann Stippel (all three SPÖ), Christian Brünner (ÖVP), Thomas Barmüller (FPÖ, later LIF) and Johannes Voggenhuber (Greens). They acted as the editorial team for the final parliamentary report (vgl. HLAVAC 1992).

123 In November 1989, the German Bundestag decided to establish the Office of Technology Assessment at the German Bundestag (TAB). Since then, it has been operated by what is now the Institute of Technology Assessment and Systems Analysis (ITAS) at the Karlsruhe Institute of Technology (KIT).

124 "In addition to its tasks, the TAU could take on the role of a 'technology assessment secretariat' for the Parliament". (Archive of the OeAW: FTB. Letter from Gunther Tichy to Werner Welzig, 17.1.1992, p. 6; (translated by authors).

125 Archive of the OeAW: FTB. Comments on proposals, letter from Heinz Fischer to Gunther Tichy of 4.1.1991.

126 Archive of the OeAW: FTB. Letter from Gunther Tichy to Heinz Fischer dated 11.1.1991.

127 Ibid.

128 Archive of the OeAW: FTB. Letter from Gunther Tichy to Heinz Fischer dated 11.1.1992. 


\begin{abstract}
"Measures for further TAs/technology assessment
Budgetary provision should enable further steps in technology assessment and related tasks to be carried out and financed in a manner commensurate with the importance of this complex of issues. A working group of the parliamentary groups is to draw up a proposal for implementing TAs in the National Council and discuss parliamentary institutionalisation. [...]"
\end{abstract}

(Hlavac 1992, Volume 2, p. 319; translated by authors)

Based on these experiences, the TAU made increased efforts to establish parliamentary TA in Austria. In the first step, the team established international contacts. In 1992, Walter Peissl, as deputy director of the TAU, took part in a conference of the UN intending to found a Technology Assessment Network (TAN) and an International Association of Technology Assessment and Forecasting Institutions (IATAFI). Furthermore, he was invited to a meeting of directors of the recently founded European Parliamentary Technology Assessment Network (EPTA) in 1993. From 1994 onwards, the ITA participated as an official EPTA observer ${ }^{129}$ in all other EPTA events (I13). A TAU-internal project on the institutionalisation of TA in Europe also falls into this period of network formation. ${ }^{130}$ For this project, the TAU staff completed several interview trips across Europe and subsequently organised, among other things, a symposium on "Parliamentary TA". However, at the national level, the "parliamentary TA" project made no progress for the time being. The 1994 national elections meant a break in relations between parliament and the Institute, as all TA supporters active up to that point were not re-elected among the members of parliament (such as the Tyrolean SP mandatary Lothar Müller). Under Tichy's leadership, the ITA did not pursue an active strategy towards parliament in the following decade. In these years, contracts with the parliament were limited to occasional appearances of ITA staff as experts in various parliamentary hearings. ${ }^{131}$

Director Michael Nentwich put the Austrian Parliament firmly back on the Institute's strategic agenda from 2007 onwards. In discussions with MPs dedicated to research, technology and innovation (FTI), and science and consumer protection, the ITA offered several support measures for the Austrian parliament. ${ }^{132}$ However, despite the fundamental interest of the FTI Committee $^{133}$, various initiatives were again thwarted by National Council elections. The electoral outcome meant a further setback in the efforts for parliamentary TA in Austria. ${ }^{134}$ While development at the national level was slow, the ITA was internationally successful. In 2010 (and again in 2014), the ITA became part of the European Technology Assessment Group (ETAG), which advises the STOA, the parliamentary TA body of the European Parliament (Wennrich 1999135). In total, the ITA has so far been involved in seven studies for the EU Parliament, such as for example on electronic democracy, cloud computing, and nano-safety.

Finally, international efforts also found resonance in Austria. In preparation for a full membership at EPTA, the ITA held talks with the Parliamentary Directorate as of 2012. ${ }^{136}$ Finally, Barbara Prammer, President of the Parliament, applied for the full membership at EPTA for Austria ${ }^{137}$ which the EPTA Council accepted in 2013. ${ }^{138}$ At the beginning of 2013, the ITA had started the publication series "ITA Dossiers", which are policy briefs primarily aimed at informing the Parliament on current technology issues. In April, it had another opportunity to present to the FTI Committee on the topic "Smart Grids and Smart Meters".

129 In the early years of the EPTA network, a distinction was made only between members and observers, only later was a distinction made between full and associate members, who attend all meetings, and observers, who are only invited to individual events.

130 It was attended by foreign and Austrian members of parliament and directors of foreign TA institutions and the proceedings were published (FALKNER u.a. 1994).

131 Of course, it is worth mentioning ITA's participation in the EPRI-Watch project from 1995 to 1998, which aimed to develop an interactive multimedia information and communication service on the information society for Members of the European Parliament, national parliaments and regional policy makers.

132 For example, the regular sending of tailor-made information on completed projects or the organisation of TA breakfasts" on current technology policy issues.

133 Inspired by these activities, an enquiry was held in 2008 on the initiative of the Chairwoman of the Committee for Research, Innovation and Technology (FIT), Michaela Sburny (Greens), with Ulla Burchardt (SPD), Member of the German Bundestag and long-standing Chair of the TA Committee there, Armin Grunwald, Head of the Office for TA at the German Bundestag, and Michael Nentwich (see Parliamentary Correspondence No 155 of 26 February 2008, parlament.gv.at/PAKT/PR/JAHR_2008/PK0155/index.shtml, 13 April 2018).

134 Nevertheless, in 2009 the ITA was invited to present itself and its offers to Parliament in the FTI Committee. Incidentally, in the same year the "2020 Strategy" of the Council for Research and Technology Development (RFTE) mentioned TA and Parliament" several times (RFTE 2009).

135 See also the 2017 updated self-description of STOA on the EPTA website: eptanetwork.org/static-html/comparative-table/countryreport/european_ parliament.html.

136 For EPTA full membership - in contrast to associated membership - a closer relationship with the respective national parliament must be demonstrated.

137 In an official letter of 7.2.2013 to her Finnish counterpart (as representative of the annually changing EPTA presidency) President Barbara Prammer (SPÖ) describes the good and developing relations with the ITA and submits the application for Austria's full membership in the EPTA.

138 On 23.9.2013, the EPTA Council finally decides to upgrade the membership of the ITA. ITA Archive: Minutes of the EPTA Council Meeting Kittilä/ Finland, 22-24.9.2013 (siehe auch RIEDLINGER 2013). 
This new dynamism continued in the following year. Michael Ornetzeder from the ITA took part in the "Roundtable on Austria's Future as a Science Location" in Parliament in April 2014 (initiated by National Council President Barbara Prammer and OeAW President Anton Zeilinger). At the same time, the Austrian MPs Ruperta Lichtenecker (Austrian Green Party (Die Grünen)) and Gerhard Deimek (Austrian Freedom Party (FPÖ) took part in the "Second Parliamentary Debate on TA" in Lisbon $^{139}$. In autumn 2014, the efforts to establish long-term cooperation with the Parliament finally bore fruit: together with the AIT (more precisely, the then Innovation Systems Department of the Austrian Institute of Technology, headed by Josef Fröhlich until 2016) as a strategic partner, the Director of the Parliament commissioned to conduct a feasibility study on the topic of "Foresight and TA for the Austrian Parliament". In addition, the consortium carried out a pilot project on "Industry 4.0" (2015) and a small study on possible current TA topics for the Parliament at the beginning of 2016. The feasibility study's result was a joint proposal to Parliament on designing a respective institutionalisation of TA for the Parliament.

In 2016, the ITA took over the EPTA Presidency for Austria for the first time for one year - a privilege granted to full members only - and, in addition to the Directors' Meeting in April, organised the annual Council Meeting and the Annual Conference on October 20-21, in the premises of the Parliament. A total of 22 Austrian and foreign members of parliament and a further 80 worldwide TA experts took part in these meetings. The ITA coordinated an EPTA report as input for the conference, which compiled and summarised national status quo reports on "the future of work in the digital age" from all EPTA member countries for the parliamentarians (EPTA 2016).

Based on the ITA and the AIT proposal and following a corresponding presidential decision in October 2016, for the first time, the Parliamentary Directorate finally prepared an international tender for consulting services in the field of foresight and TA for 2017. The ITA won this tender together with the AIT. The consortium was awarded a three-year framework contract for 2017 to 2020 to prepare regular monitoring reports on salient and parliament-relevant new technical and related societal developments. ${ }^{140}$ If necessary (and with a separate assignment), the team prepares short in-depth studies on specific issues and organises smaller information events for parliamentarians. ${ }^{141}$

\subsection{THE ITA INTERNATIONALLY: HIGHLY CONNECTED, ALMOST FROM THE BEGINNING}

Technology assessment is usually directed at society and politics at the respective national or regional level and therefore addresses specific cultural, legal, economic and societal contexts. However, many of the issues that play a role are not country-specific, such as scientific issues (health risks, ecology, etc.), ethical problems, and methodological questions that are universal in principle. International exchange and cooperation, therefore, characterise the activities of ITA in various contexts.

Project level: Accordingly, the TAU had already sought international cooperation in the early stages. The first European project under the EC's RACE programme took place as early as 1988 with British, French and Italian partners. It involved the then planned introduction of an integrated broadband communications network. This project was also the starting point for many other EC and EU projects. In total, the TAU/ITA team has participated in 47 such projects, three of which it has coordinated. The ITA team also carried out projects for the European Parliament (STOA Committee) as a European TA Group member. Besides, a few projects were carried out without external funding within the EPTA (see below).

International institutions: Besides the European Union institutions (especially the Commission and the European Parliament), the Institute also works for the OECD. As early as 1989, the TAU organised a conference on "Technology Assessment" for the OECD and the Austrian Federal Government in Vienna (cf. Figure 4). Furthermore, the NanoTrust project team, for example, has been represented in working parties on the topic of nano governance and nanosafety since 2008. It organised a policy round table for this organisation in 2009; most recently, in 2016, the ITA participated in an OECD fact-finding mission to Austria on "Digitisation: Labour, Economy and Society".

139 This discussion was organised in the framework of the EU project PACITA (Parliaments and Citizens in Technology Assessment", 2011 to 2015 with significant participation of ITA) and was intended to support the re-establishment of parliamentary TA in European countries.

140 This dynamic monitoring report, which is extended every six months, has been available since 2018 as a separate menu item Technology Assessment" on the parliament's website: parlament.gv.at/SERV/FTA/.

141 Parliament correspondence No 780 of 22.6.2017, parlament.gv.at/PAKT/PR/JAHR_2017/PK0780/index.shtml (13.4.2018) 

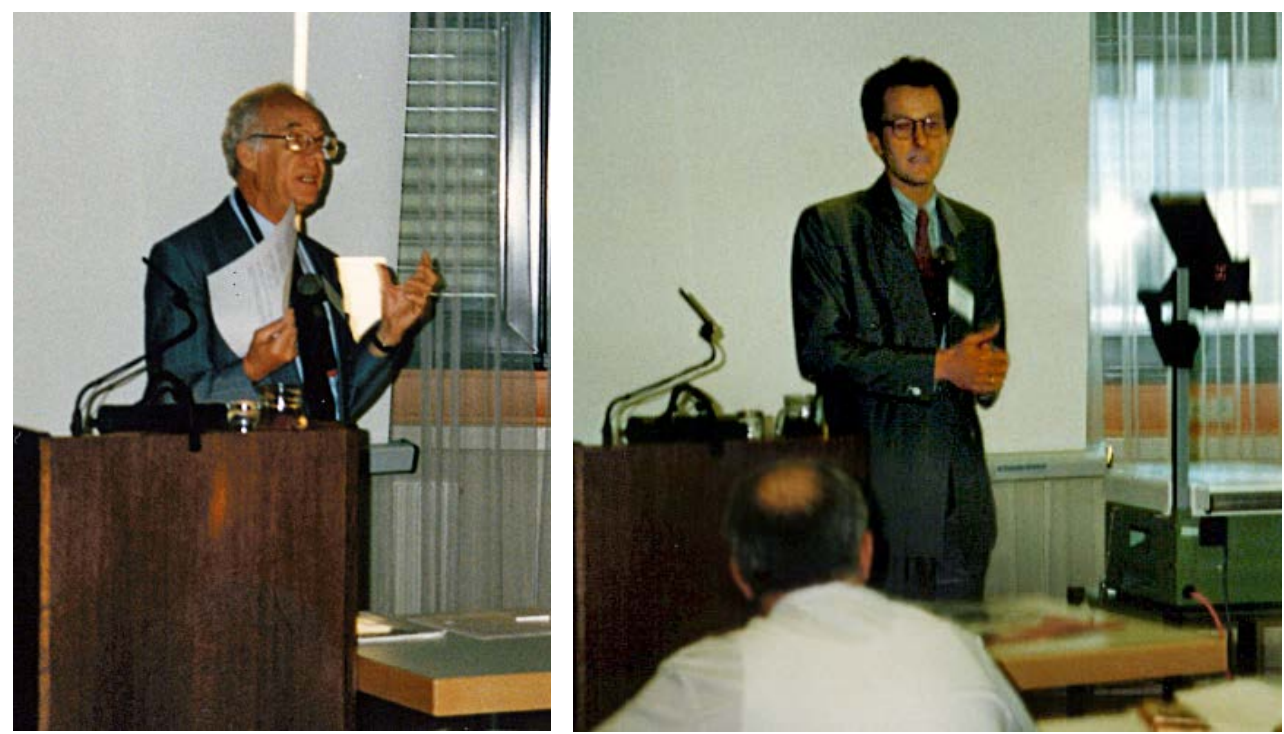

Figure 4: Ernest Braun (left) and Christian Rakos (right) present at the OECD conference on 28-30 June 1989 (Photos: W. Peissl)

Specific networks: Apart from participating in numerous national and international commissions and disciplinary networks, the TAU or ITA was/is also involved in relevant specific networks. For example, the TAU had been an associated member of EPTA (European Parliamentary Technology Assessment) since 1993. The ITA has been a full member since 2013 and benefits from the intensive biannual exchange with colleagues from all over Europe, and most recently also from the USA, Asia and Latin America, both at the parliamentary, management and practitioner level. Since the end of the 1990s, the ITA was also a member of ESTO (European Science and Technology Observatory), which became ETEPS-NET, the European Techno-Economic Policy Support Network in the mid-2000s and advised the European Commission until about 2015. The ITA worked on various projects in both networks, e.g. on "Monitoring Foresight Activities" or "Mapping the European Knowledge Base of Socioeconomic Impact Studies of Information Society Technologies". The project manager of the NanoTrust project has been sent by BMVIT to the Asian Nano Forum (ANF) as an Austrian expert on several occasions since 2011. Finally, the ITA is a founding member of the German-speaking Network Technology Assessment (NTA), founded in November 2004. In this network, the ITA team is intensively involved in various roles, from a representative in the coordination team to participate in the Working Group on Information and Communication as well as in other working groups, and in particular as host for meanwhile two of the seven biennial conferences (2008 and 2014) and four annual meetings (2007, 2008, 2014, 2017). Since 2010, an ITA staff member is on the Energy Steering Panel of EASAC, the European Academies' Science Advisory Council, representing the Austrian Academy of Sciences.

Networking of the TA community: The ITA annual conference, which has been held annually since 2001, has established itself as a well-known network node in the German-speaking area (in addition to the NTA conferences mentioned above). Furthermore, the ITA is significantly involved in the continuation of the series of (English-language) "International TA Conferences" that emerged from the EU project PACITA (Prague 2013, Berlin 2015, Cork 2017, Bratislava 2019). 


\subsection{HUMAN RESOURCES DEVELOPMENT: INTERDISCIPLINARITY AND TEAMWORK AS THE CORNERSTONES}

At the time of the founding of the technology assessment working group at the ISET in 1985, the Academy assigned three scientists (including Michael Latzer) to work with the director Ernest Braun. One more (Christian Rakos) joined in the second year, and the first administrative employee and a work contractor (Michael Nentwich) in the third year. Of the first three employees, only Rakos followed the newly founded research unit (Michael Latzer only moved to the ITA in 2004 for five years, see Section 2.6 and Figure 1). Hence, the TAU's nucleus initially consisted of only three employees (Braun and Rakos plus one administrative staff member). However, in the first year of the TAU, three more scientists were recruited, two of whom are still working at the ITA today, namely Johann Čas and Walter Peissl. By the end of 1990, the team had already grown to twelve members, including the long-standing staff members Claudia Wild (until 2006) and Helge Torgersen (until 2019). This order of magnitude remained roughly the same until 2006, with slight fluctuations (between 12 and 16). The HTA team (led by Claudia Wild) left the institute simultaneously with the change in management in that year, and created a new institute, now named the Austrian Institute for Health Technology Assessment (AIHTA). Replacing these positions and adding three people through the newly acquired NanoTrust project led to a relatively significant change in personnel in 2007/08 and at the same time to an increase from around 15 to over 20 employees due to third-party funding; from 2009, the number of employees levelled off at around 25 (see Figure 5). As of 2018, only four people from the early years of TA at the Academy were still working at the institute (Čas, Peissl, Torgersen, and Nentwich).

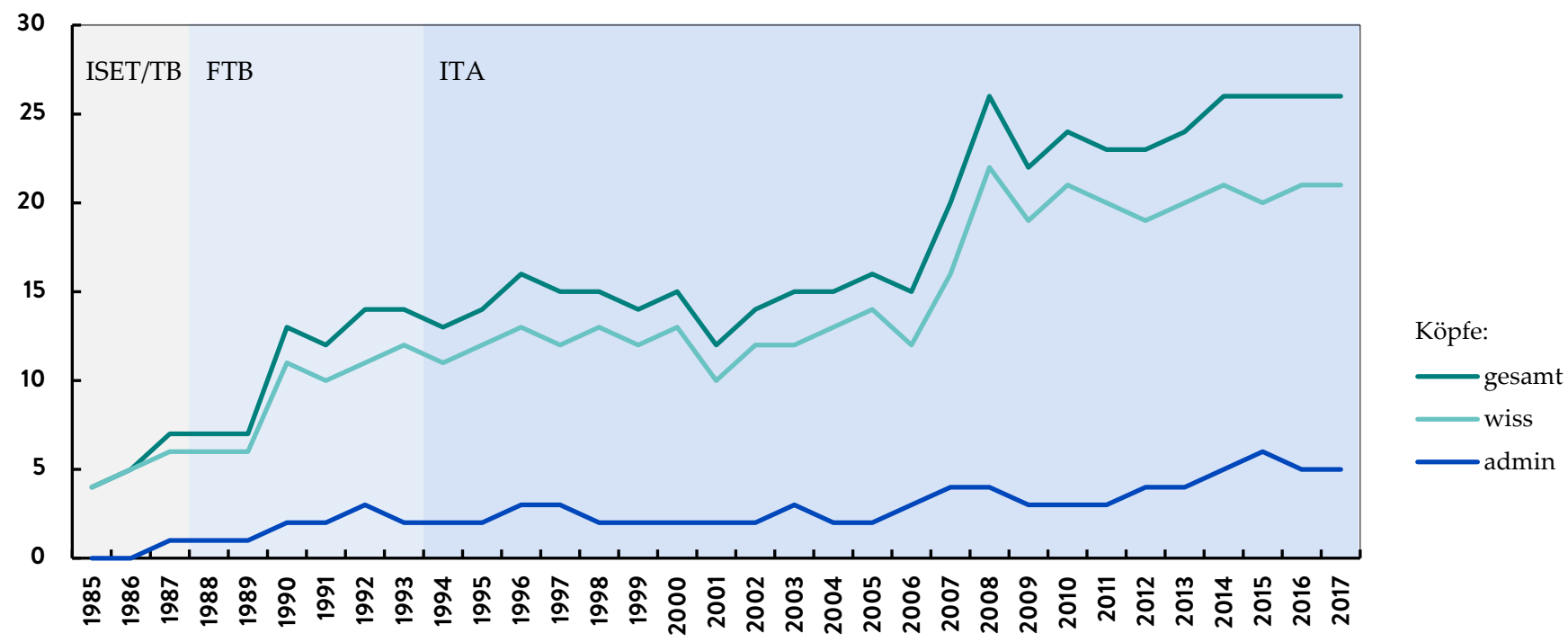

Figure 5: Personnel development of TA at the Austrian Academy of Sciences 1985-2017 (heads)

Administration: The overall growth in personnel, but also the continually increasing requirements, particularly in third-party funding management and accounting, IT infrastructure, event organisation and public relations, are reflected in the development of the Institute's administrative area, which has undergone a significant professionalisation: while the ITA started with one and a half administrative staff positions (until the mid-2000s), the new director set up a differentiated office team from 2006 onwards. This team comprises five people and has taken on tasks such as event management, project controlling, IT support and public relations (from 2014). This professionalisation in the office has enabled the Institute to continue to grow in terms of personnel and massively expand its portfolio of activities (projects, events, media work). 
Personnel statistics: If we include the years of the first working group from 1985 to 1987, 69 people were employed at the ITA by mid-2017, i.e. in just over 30 years (we have not included the additional numerous guest researchers, interns and contractors in the statistics). Of these 69, 31 are female and 38 male. The current gender ratio at the ITA is twelve female to fourteen male (three to two in the office area). The team was initially relatively young and for some, the TAU or ITA job was the first or second ever. Naturally, this has changed significantly over the years, as the team now includes both veteran seniors, who will retire in a few years, and graduates. At the end of 2017, four employees will be under 35 years of age, eleven between 35 and 45, seven between 45 and 55, five over 55. In mid-2017, Georg Aichholzer, who had been researching at the ITA since 1993, retired as the first long-term researcher.

Academic qualifications: Of the academic staff over the past 30 years, a total of four people (including the first two directors) were full university professors, and a total of nine have been or are currently holding a habilitation (in mid-2017, the ITA employed a total of four researchers with venia docendi and three Elise-Richter senor post-docs aiming at a venia docendi). Of the total of 69 employees' overtime, 35 have a doctorate. The spread across the scientific disciplines is as broad as possible following TA's multi- and interdisciplinary approach. Graduates from the following fields did research at the TAU or the ITA: physics, biology, medicine, toxicology, ecology, human ecology, process engineering, chemistry, business informatics, sociology, political science, business administration, economics, law, history, philosophy, risk management, scientific research, communications engineering, information security management, geography, information \& knowledge management.

\subsection{OUTREACH AND PUBLIC COMMUNICATION: THE ITA IS BUILDING A REPUTATION}

In the last two decades, the (social) scientific community has increasingly acknowledged that it is time to leave the proverbial ivory tower and communicate with the public. The reasons for this are manifold and range from the need to inform the public, to let them participate in the findings and even to involve them directly in research (keyword: Citizen Science) to the obligation to offer society a service in return for funding research. What began with the specialisation of science journalists and interviews with star researchers now extends to all levels of the scientific community. The rapid spread of the Internet has done much to make science potentially more visible, as practically all research institutions now reach out to the interested public on their websites (Nentwich 2010a).

In numerous projects at the ITA, the relationship between the public and science or technology development has been an important topic. The type of involvement of the Institute and the type of public addressed sometimes varies considerably. In particular, the effects of the Internet on research operations were the subject of several larger TA projects at the ITA from 1998 onwards (especially Cyberscience, Interactive Science, Living Reviews, and Cyberscience 2.0). The ITA team directly incorporated findings from these projects into the respective institute policy. The ITA had already been online since $1996 .{ }^{142}$ Over the years, social media, particularly Twitter and Facebook, have become increasingly important alongside the website, and video has been added to the list to some extent from 2014.

Communication work with different societal actors - from decision-makers in politics and administration (e.g. NanoTrust), stakeholders, citizens as participants in participatory processes, and the "general public" - is at the centre of daily TA work (Nentwich 2010b). A particular focus of ITA's work developed alongside the emergence of participatory TA. Since the mid1990s, the analysis of participation in various thematic areas has been a fixed component of the Institute's work. ${ }^{143}$ Since the mid-2000s at the latest, a differentiation and professionalisation have also taken place regarding practical implementation, with approaches developing in different directions (from advising the Austrian administration on concrete issues to 'visioneering' in connection with EU tenders and co-creation approaches with the European Commission). ${ }^{144}$

142 The comprehensive overview of activities and results, from a complete list of all publications and projects to short CVs of employees is particularly remarkable; a comprehensive modernisation of the web channel and the adaptation to the corporate design of the ITA was carried out in 2013 and to that of the Austrian Academy of Sciences in 2018.

143 See projects such as Technology policy and the public" (1995), Eurobarometer series, especially in the context of the debate on genetic engineering, Cyberscience 2.0.

144 Projects here are e.g. Techpol 2.0" (2005), CIVISTI“ and related projects (from 2007), projects on e-participation, European public sphere and media change" (2006). 
Apart from personal public appearances in the media in the early years (for example, by Gunther Tichy), the Institute initially developed hardly any systematic public relations activities. The first tentative, somewhat experimental attempts took place in the medium of radio. From December 1996 to March 2000, the ITA team produced a monthly half-hour radio programme as part of the project "RADIÖ1476 on Medium Wave" initiated by ORF Radio Ö1. The team produced a total of 31 broadcasts in four years (Nentwich 2003). ${ }^{145}$ The ITA took the second step in October 1998 with the first issue of the ITA newsletter (51 issues until June 2012), a series written by ITA scientists themselves and mainly reporting project results, events and activities in TA.

We can place the beginning of the systematic examination of public relations work in the year 2000. After several internal seminars and input from external experts, the ITA developed an encompassing PR concept (Nentwich 2000). The team subsequently launched various activities that gradually made the ITA better known to the public. Besides the already mentioned radio broadcasts and newsletters, the ITA started with occasional press releases, especially in connection with its annual conferences starting in 2001. Furthermore, the team established a rapidly growing e-mail distribution list (itanews), designed information folders, and became involved in the development of science.orf.at (2000 to 2003). From then on, it regularly took the opportunity to present itself and engage in discussions with the interested public at the Science Weeks (2000, 2002), the Long Nights of Research (2008, 2009, 2012, 2014, 2016, 2018) and the European Researchers Night (2016).

While public relations work took place alongside research activities until 2012 by dedicated scientists who were supported by the office team and partly by the Austrian Academy of Sciences public relations department, since 2013 the ITA has had its own public relations officer. This has enabled further professionalisation of the ITA's management of web, social media presence as well as its media contacts. 2016 and 2017 were the most successful years regarding ITA's media presence (Bayer 2017; Riedlinger 2018). In 2013, the ITA public relations department, together with partners from Germany, the Netherlands, Switzerland and Great Britain, established the group "European Technology Assessment Communicators (ETAC)". Within this framework, the public relations officers of the participating institutions exchange information, learn from each other and try to revive the tradition of a joint European TA newsletter - published in the early years of EPTA (from 1992) and within the framework of the PACITA project (2011-2015).

The ITA has also made an international commitment to the electronic infrastructure of the TA community worldwide. It was the first webmaster of the German-language Network Technology Assessment (NTA) from 2005 to 2013, and from 2012, it played an active role in the development of openTA, the NTA's web portal, as a beta tester and data supplier from the very beginning. The ITA was also task leader in the PACITA project for the international "TA Portal", which went online in October 2012, and has continued to look after this virtual infrastructure of the worldwide TA community as a webmaster beyond the end of the project. In April 2015, the ITA also took over the webmaster role for the worldwide EPTA network website from the Danish member and ensured a re-launch in summer 2015. In addition, the ITA has also maintained the virtual EPTA presence on Facebook and Wikipedia since 2010.

145 The concept of the programme consisted of one or two ITA staff members talking to the (fictitious) "maintenance man Max" of the Austrian Academy of Sciences in the coffee house. The topics for the ITA's programmes were derived from his current research results, picked out critical and practice-relevant aspects and worked them out for the listeners in dialogue form. 


\section{4 CONCLUSION AND OUTLOOK}

Technology assessment is a remarkable international success story. For 45 years, it has been conducted in various institutional forms, with varying degrees of proximity to politics and with different methods and approaches, primarily in Europe, but increasingly so on other continents (North and South America, Asia). Nevertheless, the historical developments of these institutions are not linear or straightforward.

Particularly because of the proximity to politics and administration, it is mainly political reasons that lead to TA institutions rising and falling. Especially those that have a direct consultative relationship with parliaments depend on the goodwill of changing majorities of the members of parliament. For example, following the example of all later TA institutions, the Office of Technology Assessment (OTA) at the US Congress, a new Republican majority in Congress, cut the budget in 1995 after 23 years of deliberations, which was tantamount to closure (Büllingen 1999; Sadowski 2015). The same happened to the Institute Society and Technology (IST) in 2012 when the majority in the Flemish regional parliament changed. ${ }^{146}$ Recently, the traditional Danish Board of Technology (DBT), whose state funding and close links with the parliament were frozen after the 2011 elections, also experienced this. The DBT only survived as an institution because of a risky recreation as a foundation (Ganzevles et al. 2012, 75ff.). However, TA facilities supported and used by the administration for many years were also closed down again. One example is the closure of the Stuttgart Academy for Technology Assessment in 2003, which worked for the Baden-Württemberg government and had been positively evaluated internationally immediately before. Another case of closure is the Working Group on Technology Assessment and Evaluation (AKTAB) at the Ministry of Science of North RhineWestphalia, set up on the initiative of the Landtag committee "Man and Technology" and collaborated successfully with it (Henning 1999). TA institutions were established and reduced at the university level, such as the BIOGUM research group in Hamburg. This group known for TA in life sciences was realigned in terms of content in 2016 after the two long-standing heads' retirement.

Against this background, it is all the more remarkable that a TA institution continues to exist over several decades and even expands in scope and grows in staff. In recent years, some TA institutions have celebrated their $25^{\text {th }}$ or $30^{\text {th }}$ anniversary, including the Office of Technology Assessment at the German Bundestag (TAB, founded in 1990) and the Office parlementaire d'évaluation des choix scientifiques et technologiques (OPECST, founded in 1983) of the French Parliament.

Austria's ITA can now also look back on a long institutional history, as described in detail in this article. Three decades passed from its beginnings as a working group (1985), the founding of the research unit (1988) and the establishment of the institute (1994) until today. Even though the Institute has never been directly dependent on politics (compared to similar institutions) and has thus been and still is less exposed, there have nevertheless been crises. Each of them could have led to the ITA no longer existing today or in a completely different form. It is undoubtedly the great merit of the Austrian Academy of Sciences that it achieved the politically desired foundation and continuation despite personnel difficulties, financial problems and diverging evaluations of the scientific nature and usefulness of TA. This achievement is even more remarkable as the combination of science academies and TA institutions can potentially lead to conflicts. While academies, among other things, pursue "policy for science", i.e. as stakeholders provide political input into science policy, the core task of TA is "science for policy", i.e. the non-interest-driven, science-based input. Both perspectives can, but do not always need to be in harmony. The resulting crises have been reported in this article (see in particular Sections 2.3, 2.4 and 2.7). Remarkably, almost all the causes mentioned above can be attributed to personnel turbulence to lack of resources to political questioning.

It has, however, never been claimed that technology assessment has lost the legitimacy to continue. The above-average success of the ITA in raising third-party funds, the lively interest of the Austrian ministries, the European Union, the Parliament, and the meanwhile firm institutional backing at the Academy clearly show that the ITA's unique approach - characterised by interdisciplinarity, teamwork, scientific excellence, independence, multi-perspectivity, critical spirit and farsightedness - is in high demand in the $21^{\text {st }}$ century. As technological development continues to advance, questions will continue to arise in social and political debates in the future for which TA can provide balanced, future-oriented answers and options.

146 See the IST archive website: ist.vito.be/en/index.html (12.4.2018). 
Against this background, the ITA's development plan envisages further expanding its capacities to accompany society and politics on their way into the future in the best way possible. In particular, the ITA envisages gradual growth to deal with more topics and be prepared for short-term requests from Parliament. The next few years will be challenged by the generational changes among the TA researchers at the ITA. In 2017, the first of the long-standing research assistants retired, and further retirements are imminent in the coming years. Against the background of the specific requirements that characterise TA work, these future departures mean a loss of a great deal of expertise and experience, which will gradually be compensated for by younger and committed staff. The staffing level in 2018 already includes a good mix of younger seniors and young researchers, which leads to the expectation that the Institute will maintain its position as a nationally and internationally renowned scientific TA institution in the following decades. 


\section{LIST OF ABBREVIATIONS}

Note: The abbreviations are of 2017; some institutions may have changed their names since.

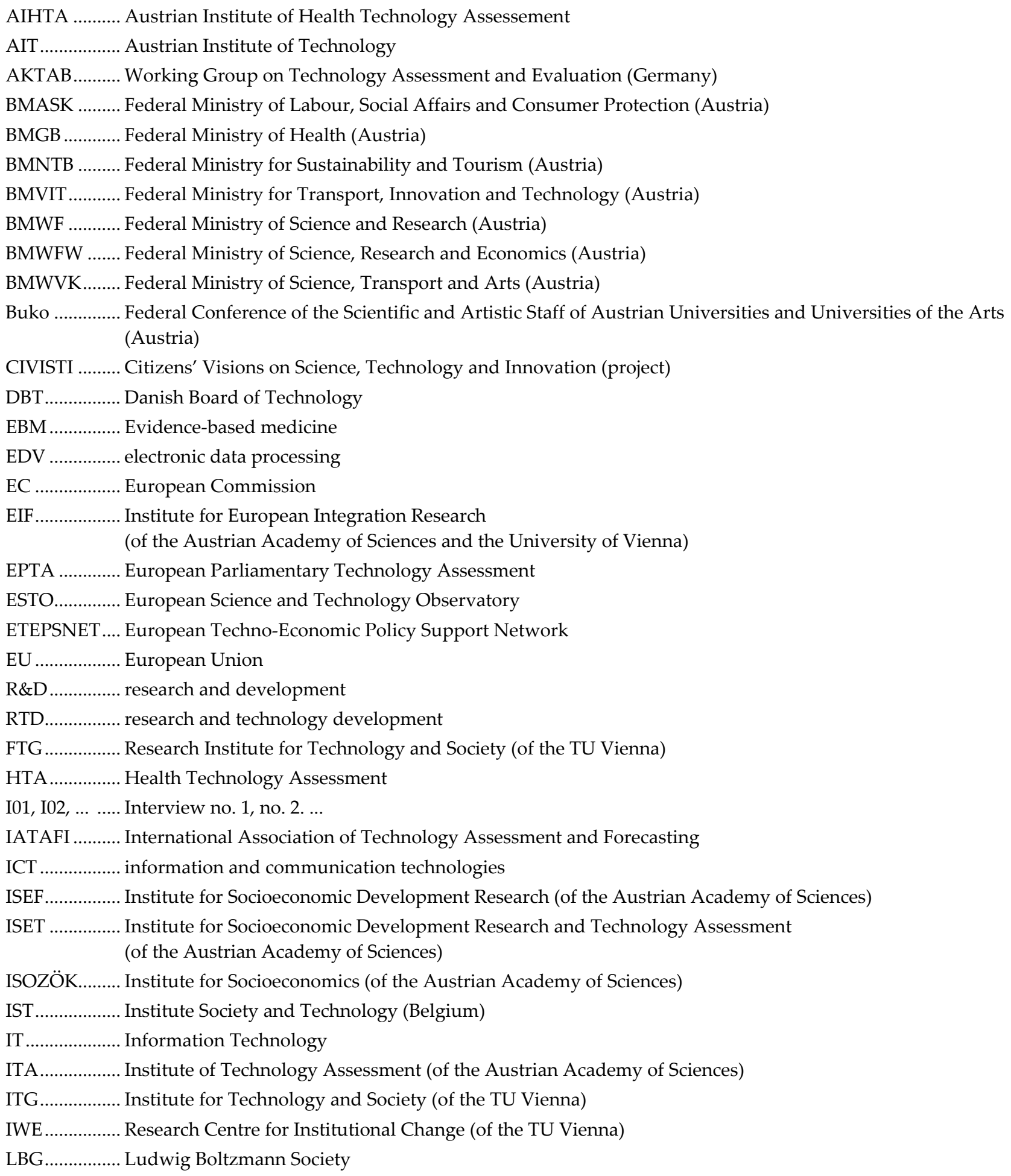




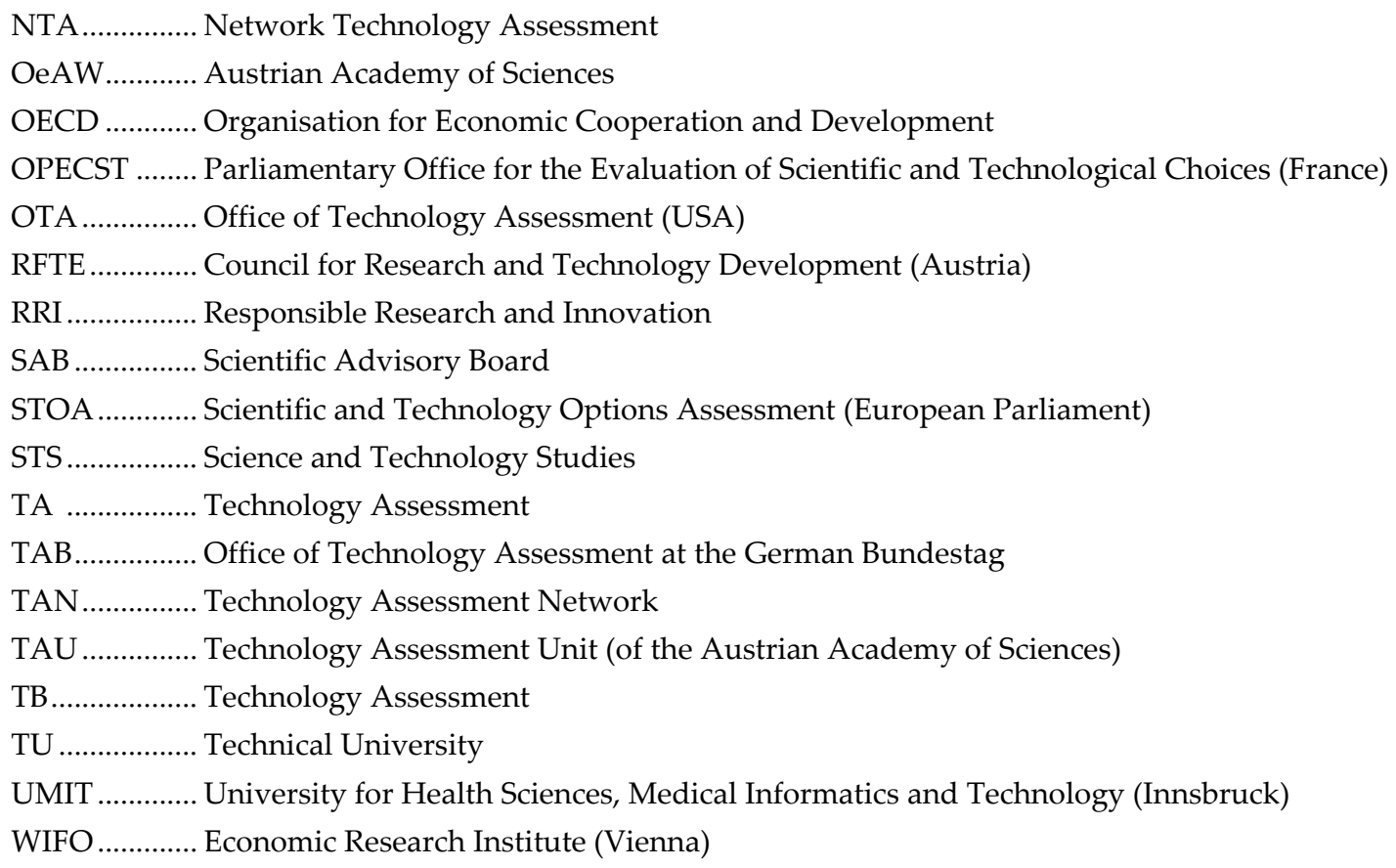




\section{BIBLIOGRAPHY}

Aichholzer, Georg (2001): The Austrian foresight program: organization and expert profile. In: International Journal of Technology Management 21(7/8), 739-755.

Aichholzer, Georg/Torgersen, Helge (1994): 'Sozialverträgliche' Technikgestaltung - zwischen Rhetorik und Realisierung, Editorial für das Schwerpunktheft 'Sozialverträgliche Technikgestaltung'. In: Österreichische Zeitschrift für Soziologie 19(4), 3-7.

Bayer, Thomas (2017): ITA in den Medien: Das waren die Top-Themen. News; last update: 2017-02-16 oeaw.ac.at/ita/ueberuns/aktuelles/ita-in-den-medien-das-waren-die-top-themen/.

Braun, Ernest (1984): Die Technologiepolitik und ihr Informationsbedarf. In: Bundesministerium für Bildung und Forschung (Ed.): Nationalfeiertagssymposium 'Technik und Gesellschaft', 26 October. Vienna.

Braun, Ernest/MacDonalds, Stuart (1982 [1978]): Revolution in miniature. The history and impact of semiconductor electronics. 2. ed. Cambridge. Braun, Ernest/Rakos, Christian/Nentwich, Michael (1988): Technikbewertung und Umweltverträglichkeitsprüfung - Ein internationaler Vergleich. Vienna (Schriftenreihe der Forschungsinitative des Verbundkonzerns, vol. 1).

Bruckmann, Gerhard (1971): Exakte Methoden in der Futurologie. In: Anzeiger der Österreichischen Akademie der Wissenschaften/ Philosophisch-historische Klasse 108(25), 283-299.

Büllingen, Franz (1999): Das Office of Technology Assessment (OTA). In: Bröchler, Stephan/Simonis, Georg/Sundermann, Karsten (Ed.): Handbuch Technikfolgenabschätzung. Berlin, 411-416.

EPTA (European Parliamentary Technology Assessment) (2016): The Future of Labour in the Digital Era. Ubiquitous Computing, Virtual Platforms, and Real-time Production. May, Vienna: ITA epub.oeaw.ac.at/ita/ita-projektberichte/EPTA-2016-Digital-Labour.pdf.

Falkner, Gerda/Peissl, Walter/Torgersen, Helge (Eds.) (1994): Parlamentarische Technikfolgen-Abschätzung in Europa (E-book). Vienna epub.oeaw.ac.at/?arp=0x00043020.

Fleißner, Peter (1973): Kommission für sozio-ökonomische Entwicklungsforschung. Eine Kommission der Österreichischen Akademie der Wissenschaften. Österreichische Hochschulzeitung, 1 April.

Ganzevles, Jurgen/Est, Rinie van/Brom, Frans/Adam, Frédéric/Attila, Zsigmond/Almeida, Mara/Barland, Marianne/Bütschi, Danielle/ Damianova, Zoya/Delvenne, Pierre/Domínguez, Ferran/Evers, Johan/Feresin, Emiliano/Fixdal, Jon/Fodor, Katalin/Hebakova, Lenka/Hennen, Leonhard/Jacobi, Anders/Kégler, Ádám/Leichteris, Edgaras/Klüver, Lars/Kozarev, Ventseslav/López, Belén/Nentwich, Michael/Nierling, Linda/O'Reilly, Paidi/Folker, Marie Paldam/Peissl, Walter/Rosskamp, Benedikt/Sotoudeh, Mahshid (2012): TA Practices in Europe.

Deliverable 2.2 of the PACITA (Parliaments and Civil Society in Technology Assessment) project. sollicited by: European Commission, September: PACITA Consortium pacitaproject.eu/wp-content/uploads/2013/01/TA-Practices-in-Europe-final.pdf.

Henning, Klaus/Fuchs-Frohnhofen, Paul/Olbertz, Ellen (1999): Der AKTAB NRW. In: Bröchler, Stephan/Simonis, Georg/Sundermann, Karsten (Ed.): Handbuch Technikfolgenabschätzung. Berlin, 451-457.

Hlavac, Elisabeth (1992): Bericht der Parlamentarischen Enquete-Kommission betreffend „Technikfolgenabschätzung am Beispiel der Gentechnologie", 3 volumes, No. 740 BlgStenProt XVIII. GP, Vienna: Österreichisches Parlament.

Kastenhofer, Karen/Bauer, Anja/Capari, Leo/Fuchs, Daniela/Gazsó, André/Nentwich, Michael/Peissl, Walter/Sinozic, Tanja/Sotoudeh, Mahshid (2018): Politikberatung am Institut für Technikfolgen-Abschätzung (Pol[ITA]). Internal project report, No. ITA-18-02, Vienna: ITA.

Kolm, Paul/Peissl, Walter/Torgersen, Helge/Wagner, Ina (1995): Öffentlichkeit und Technologiepolitik - Die Informationsgesellschaft - ein Konzept der BürgerInnen entsteht. November, Vienna : ITA.

Meadows, Donella H/Meadows, Dennis L/Randers, Jorgen/Behrens, William W (1972): The limits to growth. A report for the Club of Rome's project on the predicament of mankind. New York.

Nentwich, Michael (2000): Öffentlichkeitsarbeit des Instituts für Technikfolgen-Abschätzung. Internes Konzept, ITA, 6 August, Vienna.

Nentwich, Michael (2003): Radio1476 als Beispiel für einen innovativen und partizipativen Umgang mit einem alten Medium. Online-Paper im Rahmen der Themenschiene „Mediengesellschaft“ des Demokratiezentrums Wien. [last vistied: 24.1.2018]

demokratiezentrum.org/index.php?id=417Eindex $=631$.

Nentwich, Michael (2010a): Neue Fenster im Elfenbeinturm? Wissenschaftskommunikation und Web 2.0. In: Bieber, Christoph/Drechsel, Benjamin/Lang, Anne (Eds.): Kulturen im Konflikt. Claus Leggewie revisited. Bielefeld, 421-428.

Nentwich, Michael (2010b): Technikfolgenabschätzung 2.0. In: Technikfolgenabschätzung - Theorie und Praxis 19(2), 74-79,

tatup.de/index.php/tatup/article/view/859. 
Nentwich, Michael (2016): The European Parliamentary Technology Assessment network (EPTA). In: Tiihonen, Paula (Ed.): For the next generations. Report of the International Seminar in the Finnish Parliament 7-8 June 2016. Helsinki (Publications of the Committee for the Future, vol.5/2016), 106-110, eduskunta.fi/FI/tietoaeduskunnasta/julkaisut/Documents/tuvj_5+2016.pdf.

Nentwich, Michael/Peissl, Walter (Eds.) (2005): Technikfolgenabschätzung in der österreichischen Praxis. Festschrift für Gunther Tichy. Verlag der Österreichischen Akademie der Wissenschaften, Vienna.

Nowotny, Helga (1979): Kernenergie: Gefahr oder Notwendigkeit. Frankfurt a.M.

Peissl, Walter (1997): Das Institut für Technikfolgen-Abschätzung der Österreichischen Akademie der Wissenschaften. In: von Westphalen, Raban Graf (Eds.): Technikfolgenabschätzung als politische Aufgabe. 3. ed., München/Vienna, Oldenbourg, 305-322.

Peissl, Walter (2004): Netzwerk TA gegründet. ITA-Newsletter, December, 10.

Peissl, Walter/Nentwich, Michael (2005): 20 Jahre Technikfolgenabschätzung in Österreich. In: Nentwich, Michael/Peissl, Walter (Eds.): Technikfolgenabschätzung in der österreichischen Praxis. Festschrift für Gunther Tichy. Vienna, 11-32 epub.oeaw.ac.at/0xc1aa500d_0x00107759.pdf.

Peissl, Walter/Tichy, Gunther (1999): Das Institut für Technikfolgen-Abschätzung der Österreichischen Akademie der Wissenschaften. In: Bröchler, Stephan/Simonis, Georg/Sundermann, Karsten (Eds.): Handbuch Technikfolgenabschätzung. Berlin, 479-486.

Pelinka, Anton (1986): Hainburg - mehr als nur ein Kraftwerk: Bewertung der Ereignisse um den Kraftwerksbau in Hainburg. In: Kohl, Andreas/Karner, Stefan/Ofner, Günther/Halper, Dietmar (Eds.): Österreichisches Jahrbuch für Politik 1985, Vienna, 93-107.

Rakos, Christian (1988): Recent developments of technology assessment and environmental impact assessment in Europe; in: Project Appraisal 3(4), 205-209.

RFTE (2009): Strategie 2020. Rat für Forschung und Technologieentwicklung, rat-fte.at/tl_files/uploads/Strategie/090824_FINALE\%20VERSION_FTI-Strategie2020.pdf.

Riedlinger, Denise (2013): Full EPTA membership for Austria. ITA-News, 25.9.

oeaw.ac.at/en/ita/detail/news/full-epta-membership-for-austria.

Riedlinger, Denise (2018): ITA in den Medien: Top-Themen 2018. News; last update: 2018-01-24

oeaw.ac.at/ita/detail/news/das-ita-in-den-medien-top-themen-2017.

Sadowski, Jathan (2015): Office of Technology Assessment: History, implementation, and participatory critique. In: Technology in Society 42, 9-20.

Taschwer, Klaus (2012), Noch ein Mitglied trat aus. Der Standard, 9 May derstandard.at/1336435375073/OeAW-Noch-ein-Mitglied-trat-aus.

Tichy, G. (2001): The decision Delphi as a tool of technology policy - The Austrian experience. In: International Journal of Technology Management (21 (7/8)), 765-766.

Tichy, Gunther (1997): Das Institut für Technikfolgen-Abschätzung. In: Hittmair, Otto/Hunger, Herbert (Eds.): Akademie der Wissenschaften. Entwicklung einer österreichischen Forschungsinstitution, Vienna.

Tichy, Gunther (2004): Technikfolgen-Abschätzung: Entscheidungshilfe in einer komplexen Welt. ITA manu:script No. ITA-04-02, Vienna, oeaw.ac.at/ita/pdf/ita_04_02.pdf.

Tichy, Gunther (2005): TA und Politik: Einfluss durch die Hintertür? Fünfte Österreichische TA-Konferenz (TA'05), 30 May, Akademie der Wissenschaften, Vienna oeaw.ac.at/ita/veranstaltungen/vergangene-veranstaltungen/konferenzen/ta05-konferenz.

Tichy, Gunther (2016): Geht der Arbeitsgesellschaft die Arbeit aus? In: WIFO-Monatsberichte 89(12), 853-871.

Torgersen, Helge/Mikl, Markus (1992): Zusammenfassungen der Sitzungsprotokolle und der eingegangenen Stellungnahmen für die parlamentarische Enquete-Kommission 'Technikfolgen-Abschätzung am Beispiel der Gentechnik'. No. 740 der Blg. zu den Stenogr. Protok. d. NR XVIII GP, Vienna.

Torgersen, Helge/Mikl, Markus/Peissl, Walter (1992): Gutachten der FTB für die parlamentarische Enquete-Kommission 'TechnikfolgenAbschätzung am Beispiel der Gentechnik'. No. 740 der Blg. zu den Stenogr. Protok. d. NR XVIII GP, WViennaien: Forschungsstelle für Technikbewertung.

Torgersen, Helge/Seifert, Franz (1997): Aversion Preceding Rejection: results of the Eurobarometer survey 39.1 on biotechnology and genetic engineering in Austria. In: Public Understanding of Science (6), 1-12.

Wennrich, Christine (1999): STOA - Die TA-Einrichtung des Europäischen Parlaments. In: Bröchler, Stephan/Simonis, Georg/Sundermann, Karsten (Eds.): Handbuch Technikfolgenabschätzung. Berlin, 529-534. 

ÖAW



WWW.OEAW.AC.AT 